University of Wollongong

Research Online

Faculty of Engineering and Information

Faculty of Engineering and Information

Sciences - Papers: Part B

Sciences

2018

\title{
A model-based optimal control strategy for ground source heat pump systems with integrated solar photovoltaic thermal collectors
}

Lei Xia

University of Wollongong, Ix873@uowmail.edu.au

Zhenjun Ma

University of Wollongong, zhenjun@uow.edu.au

Georgios Kokogiannakis

University of Wollongong, gkg@uow.edu.au

Shugang Wang

Dalian University of Technology, shugang@uow.edu.au

Xuemei Gong

Zhejiang University, xgong@uow.edu.au

Follow this and additional works at: https://ro.uow.edu.au/eispapers1

Part of the Engineering Commons, and the Science and Technology Studies Commons

Research Online is the open access institutional repository for the University of Wollongong. For further information contact the UOW Library: research-pubs@uow.edu.au 


\title{
A model-based optimal control strategy for ground source heat pump systems with integrated solar photovoltaic thermal collectors
}

\author{
Abstract \\ This paper presents a model-based optimal control strategy for ground source heat pump systems with \\ integrated solar photovoltaic thermal collectors (GSHP-PVT). The control strategy was formulated using \\ simplified adaptive models and a genetic algorithm (GA) to identify energy efficient control settings for \\ GSHP-PVT systems. The simplified adaptive models were used to predict the system energy performance \\ under various working conditions and control settings, and the model parameters were continuously \\ updated using the recursive least squares (RLS) estimation technique with exponential forgetting. The \\ performances of the adaptive models and the control strategy were evaluated based on a virtual \\ simulation system representing a GSHP-PVT system for residential applications. The performance of the \\ major adaptive models was also validated using the experimental data. The results showed that the \\ simplified adaptive models used were able to provide acceptable energy performance prediction. The \\ optimal control strategy can save energy consumption by $7.8 \%, 7.1 \%$ and $7.5 \%$, and increase electricity \\ generation by $4.4 \%, 6.2 \%$ and $5.1 \%$, during the whole cooling, heating and transition periods considered, \\ respectively, in comparison to a conventional control strategy. The findings obtained from this study could \\ be potentially used to drive the development of advanced control strategies suitable for real-time \\ applications. \\ Disciplines \\ Engineering | Science and Technology Studies

\section{Publication Details} \\ Xia, L., Ma, Z., Kokogiannakis, G., Wang, S. \& Gong, X. (2018). A model-based optimal control strategy for \\ ground source heat pump systems with integrated solar photovoltaic thermal collectors. Applied Energy, \\ 228 1399-1412.
}




\title{
A model-based optimal control strategy for ground source heat pump
}

\section{systems with integrated solar photovoltaic thermal collectors}

\author{
Lei Xia ${ }^{\mathrm{a}}$, Zhenjun Ma ${ }^{\mathrm{a}, *}$, Georgios Kokogiannakis ${ }^{\mathrm{a}}$, Shugang Wang ${ }^{\mathrm{b}}$, Xuemei Gong ${ }^{\mathrm{c}}$ \\ ${ }^{\mathrm{a}}$ Sustainable Buildings Research Centre, University of Wollongong, 2522, Australia \\ ${ }^{\mathrm{b}}$ Faculty of Infrastructure Engineering, Dalian University of Technology, 116024, China \\ ${ }^{c}$ Building Energy Conservation Research Institute, Ningbo University of Technology,
}

\author{
315211, China \\ *Email: zhenjun@uow.edu.au
}

\begin{abstract}
This paper presents a model-based optimal control strategy for ground source heat pump systems with integrated solar photovoltaic thermal collectors (GSHP-PVT). The control strategy was formulated using simplified adaptive models and a genetic algorithm (GA) to identify energy efficient control settings for GSHP-PVT systems. The simplified models were used to predict the system energy performance under various working conditions and control settings, and the model parameters were continuously updated using the recursive least squares (RLS) estimation technique with exponential forgetting. The performances of the adaptive models and the control strategy were evaluated based on a virtual simulation system representing a GSHP-PVT system for residential applications. The performance of the major adaptive models was also validated using the experimental data. The results showed that the simplified adaptive models used were able to provide acceptable energy performance prediction. The optimal control strategy can save energy consumption by $7.8 \%, 7.1 \%$ and 7.5\%, and increase electricity generation by $4.4 \%, 6.2 \%$ and $5.1 \%$, during the whole cooling, heating and transition periods considered, respectively, in comparison to a conventional control strategy. The findings obtained from this study could be potentially used to drive the development of advanced control strategies suitable for real-time applications.
\end{abstract}


Keywords: Optimal control; Adaptive models; GSHP; PVT; Genetic algorithm.

\section{Nomenclature}

$a_{1}-a_{3} \quad$ coefficients

$b_{0}-b_{4} \quad$ coefficients

$C_{0}-C_{2} \quad$ coefficients

$A_{p v t} \quad$ total area of the PVT collector $\left(\mathrm{m}^{2}\right)$

COP coefficient of performance

$C_{p} \quad$ specific heat of water $(\mathrm{kJ} / \mathrm{kg} \mathrm{K})$

E electricity generation (W)

f fitness function

$F_{R} \quad$ heat removal efficiency factor

$G_{t} \quad$ incident solar radiation on the PVT collector $\left(\mathrm{W} / \mathrm{m}^{2}\right)$

$h \quad$ enthalpy $(\mathrm{kJ} / \mathrm{kg})$

$h_{s} \quad$ saturated air enthalpy at the temperature $T_{s}(\mathrm{~kJ} / \mathrm{kg})$

$J \quad$ cost function

$K \quad$ thermal conductivity $(\mathrm{W} / \mathrm{m} \mathrm{K})$

L $\quad$ depth (m)

$M \quad$ mass flow rate $(\mathrm{kg} / \mathrm{s})$

$m \quad$ number of simulation time steps

$M_{p v t} \quad$ mass flow rate of the water tank recharge $(\mathrm{kg} / \mathrm{s})$

$N \quad$ number of boreholes

$n \quad$ number of immersed heat exchangers

Q heat transfer rate (W) 


\begin{tabular}{|c|c|}
\hline$q_{\text {cond }}$ & heat transfer rate per unit length (W/m) \\
\hline$Q_{\text {cooling }}$ & cooling load $(\mathrm{kW})$ \\
\hline$Q_{\text {heating }}$ & heating load $(\mathrm{kW})$ \\
\hline$Q_{u}$ & useful heat gain (W) \\
\hline$T$ & temperature $\left({ }^{\circ} \mathrm{C}\right)$ \\
\hline$T_{s}$ & equivalent coil surface temperature $\left({ }^{\circ} \mathrm{C}\right)$ \\
\hline$U A$ & overall heat transfer coefficient $(\mathrm{kW} / \mathrm{K})$ \\
\hline$U_{L}$ & overall loss coefficient $\left(\mathrm{W} / \mathrm{m}^{2} \mathrm{~K}\right)$ \\
\hline$V$ & loss function \\
\hline$W$ & power consumption (W) \\
\hline$x$ & regression variable \\
\hline$y$ & observed variable \\
\hline$(\tau \alpha)_{P V}$ & transmittance-absorptance of the PV cell \\
\hline \multicolumn{2}{|c|}{$\alpha, \beta, \gamma, \theta, \phi \quad$ coefficients } \\
\hline$\lambda$ & forgetting factor \\
\hline$\varphi$ & temperature coefficient \\
\hline$\eta$ & efficiency \\
\hline
\end{tabular}

\section{Subscripts}

$\begin{array}{ll}a & \text { air } \\ \text { amb } & \text { ambient } \\ b & \text { borehole } \\ c & \text { cell } \\ d & \text { design } \\ \text { est } & \text { estimation }\end{array}$




\begin{tabular}{|c|c|}
\hline$g$ & ground heat exchanger \\
\hline$g a$ & energy gain \\
\hline$g r$ & ground recharge \\
\hline$H P$ & heat pump \\
\hline$h x$ & heat exchanger \\
\hline in & inlet \\
\hline$l$ & load side \\
\hline$o$ & outer ground cylinder \\
\hline out & outlet \\
\hline pu & pump \\
\hline$P V T$ & photovoltaic thermal collector \\
\hline$p v$ & photovoltaic \\
\hline$r$ & reference \\
\hline$s$ & source side \\
\hline set & set-point \\
\hline so & soil \\
\hline$T K$ & tank \\
\hline$t$ & trial \\
\hline th & thermal \\
\hline tot & total \\
\hline$w$ & water \\
\hline
\end{tabular}

\section{Introduction}

Ground source heat pump (GSHP) systems are well known as one of the most energy efficient and environmentally friendly technologies and have been widely applied in various 
buildings around the world [1-3]. Solar photovoltaic-thermal (PVT) collectors which combine photovoltaic (PV) panels and solar thermal collectors are able to produce both electricity and thermal energy simultaneously [4]. By appropriately integrating both advanced energy techniques, a hybrid GSHP-PVT system could provide cooling and heating as well as domestic hot water (DHW) efficiently, and offset the need of grid electricity and alleviate the ground thermal imbalance.

During the last decade, an increasing number of studies have been carried out on the development of optimal control strategies for stand-alone GSHP and hybrid GSHP systems. For instance, Sundbrandt [5] developed a model predictive control (MPC) strategy for a GSHP system to minimize the system power consumption while maintaining the indoor air temperature and DHW temperature at the desired levels. In this MPC controller, a Mixed Integer Quadratic Programming (MIQP) was used to solve the optimization problem. Sivasakthivel et al. [6] employed a Taguchi method to optimize the operating parameters of GSHP systems. The optimal operating parameters were identified using Signal-to-Noise ratio and Analysis of Variance. Xia et al. [7] developed a model-based control strategy to optimize the outlet water temperature of vertical ground heat exchangers (GHEs) and the source side flow rate of a GSHP system. A hybrid optimization technique integrating a performance mapbased near-optimal strategy and the exhaustive search method was used to search for the optimal control settings. Gao et al. [8] proposed an optimal control strategy for a small capacity GSHP system to minimize its total energy consumption. A self-defined optimization algorithm was used to identify the optimal set-point of the chilled water return temperature and the width of the water temperature control band. Hu et al. [9] proposed a model-free control strategy based on extremum seeking control scheme for a cooling tower assisted GSHP system to optimize cooling tower fan speed and water pump speed. Ikeda et al. [10] developed an optimization strategy to determine the operation of a hybrid GSHP system with 
three heat pump units, an air-source heat pump (ASHP) and an auxiliary boiler, using an epsilon-constrained differential evolution with random jumping. Gang and Wang [11] developed a model-based control method for a cooling tower assisted GSHP system to regulate the operation of the GHEs and the cooling tower, in which artificial neural network (ANN)-based GHE models were used to predict the outlet water temperature of the GHEs. Weeratunge et al. [12] developed an MPC controller for the intermittent operation of a solar assisted GSHP system. The MPC controller was formulated using simplified mathematical models developed based on the experimental results and a mixed integer linear programming. The results from the aforementioned studies demonstrated the importance of the control strategies for performance optimization of GSHP systems and these control strategies generally outperformed conventional control strategies commonly used in terms of energy savings.

The effectiveness and performance of hybrid GSHP-PVT systems have been investigated in a number of studies [13-15]. The optimal control of such systems, however, has not been extensively studied. Entchev et al. [16] proposed an artificial neural network (ANN)-based method to control a GSHP-PVT system in a single house located in Ottawa (Canada). The results showed that the ANN-based strategy could reduce the primary energy consumption and carbon dioxide equivalent emissions by up to $36 \%$, and the operating cost by up to $81 \%$ when compared to a conventional on-off control. Putrayudha [17] developed a fuzzy logic controller to minimize the energy consumption of a GSHP-PVT system in a single residential house in Incheon, South Korea. The results showed that this fuzzy logic controller was able to reduce the annual energy consumption by $18.3 \%$ in comparison to a conventional on-off control. Due to the relatively high initial investment of both GSHP systems and PVT collectors, which makes the short-term economics of such systems unattractive, optimal control together with design optimization of hybrid GSHP-PVT systems is becoming more 
important.

The model-based approach has been widely used in the HVAC field to achieve energy efficient control with acceptable robustness $[18,19]$. The model-based control approach generally employs different types of models to estimate system energy performance and dynamics to the changes of control settings $[20,21]$. The models used can vary from black box models to detailed physical models dependent on the control accuracy and computational efficiency required [22]. For online control of hybrid GSHP-PVT systems, it is important to develop relatively simple, yet reliable, models to capture the dynamic behavior of the system within the entire working range.

The development of online identification techniques allows the models to be reasonably simple, and self-tuning techniques can be used to reduce the uncertainty of the models since new measured data can be continuously utilized to identify and update the model parameters [23]. Simplified adaptive models which combine online identification and self-tuning techniques have been developed and employed to formulate optimal control strategies for HVAC systems. For instance, Wang and Jin [23] developed an optimal control strategy for variable air volume air-conditioning systems. The incremental dynamic self-tuning models were used to predict the system performance and the model parameters were updated using the recursive least squares (RLS) estimation technique with exponential forgetting. Soyguder and Alli [24] used an adaptive network based fuzzy inference system to predict the required fan motor speed of an air conditioning system to minimize the energy consumption and the required damper gap rate to obtain the desired indoor temperature. The adaptive learning parameters were updated based on the gradient learning rules. Yan et al. [25] proposed a general adaptive optimal control model for building cooling and heating systems. In this model, the fuzzy self-tuning forgetting factor method was used to identify and update the operation parameters, and a genetic algorithm (GA) was used to find the optimal values of the 
control variables. In the model-based control strategy for central chiller plants developed by Ma and Wang [20], the simplified linear component models were trained and updated by using the RLS estimation technique with exponential forgetting, and then used to estimate the system energy performance and response to the changes of control settings and working conditions. A performance-based parameter tuning method of a model-driven proportionalintegral-derivative (PID) control system was proposed by Zhao et al. [26] to improve the reference signal tracking and disturbance rejection, in which two performance parameters were tuned using an Integral of Time Absolute Error (ITAE) zero-position-error optimal tuning and noise effect minimizing method. In the online optimal control strategy for a variable refrigerant flow and variable air volume combined air conditioning system developed by Zhu et al. [27], the simplified adaptive component models were used for performance prediction and a GA was used to search for the optimal control settings. The results from these studies demonstrated that the model-based optimal control strategies using self-tuning adaptive models and online parameter estimation techniques can provide a better and more robust control performance, in comparison to traditional control strategies.

This paper aims to develop an optimal control strategy for hybrid GSHP-PVT systems. The control strategy was formulated using simplified adaptive models and a GA to identify energy efficient control settings. The simplified adaptive models were selected and used as the performance predictors and the model parameters were continuously updated by using the RLS estimation with exponential forgetting. To the best of our knowledge, this is the first time that a model-based control strategy using adaptive models was developed to systematically optimize the operation of hybrid GSHP-PVT systems. The performance of this strategy was tested and evaluated based on a virtual simulation environment representing a GSHP-PVT system for residential applications. The results obtained from this study could be potentially used to drive the development of advanced strategies for real-time control and 
optimization of hybrid GSHP-PVT systems.

\section{Description of the GSHP-PVT system}

A GSHP system with integrated water-based PVT collectors, as shown in Fig. 1, was used to provide heating, cooling, and domestic hot water (DHW) for a heating dominated residential building under Melbourne (Australia) climatic conditions. This hybrid system was sized using the design optimization strategy developed in a previous study [28].

This system mainly consists of a water-based glazed PVT collector with a total area of $54 \mathrm{~m}^{2}$, a water-to-water heat pump unit with the nominal heating and cooling capacities of $14.4 \mathrm{~kW}$ and $12.6 \mathrm{~kW}$ respectively, a ground heat exchanger (GHE) system equipped with four single U-tube vertical GHEs with a depth of $80 \mathrm{~m}$ each, a $250 \mathrm{~L}$ water tank with two immersed heat exchangers, three variable speed water pumps, an indoor air-handling unit (AHU) and an electric water heater. This system can operate under different modes, as described in Table 1, to provide the functional requirements to the house through on-off control of the isolation valves.

\section{Formulation of the optimal control strategy}

\subsection{Outline of the optimal control strategy}

Fig. 2 illustrates the overall optimization process of the control strategy, in which the system operation mode presented in Table 1 was first determined based on the given working condition. The model-based performance optimizer, which consists of model-based performance predictors, model parameter estimators, operating constraints, cost function estimators and a GA optimizer, was then used to identify the energy efficient control settings. The parameters of the adaptive performance models were continuously identified and updated using the latest measurements and the RLS estimation technique with exponential forgetting [29]. The adaptive performance models used included a simplified water-to-water heat pump model, a GHE model, a water-based PVT model, a fictitious global AHU coil model, an 
immersed heat exchanger model and water pump models. Since GA is known as an efficient optimization algorithm that can provide good solutions with random initialization and has been successfully applied in a number of building HVAC related optimization studies [20, 3032], a GA optimizer was used to seek the optimal solution of the optimization problem. The control settings optimized were the heat pump load side supply water temperature $\left(T_{l, i n, s e t}\right)$, the heat pump source side supply water temperature $\left(T_{s, \text { in,set }}\right)$, water mass flow rate of the PVT collector $\left(M_{p v t}\right)$ and water mass flow rate for the ground recharge $\left(M_{g r}\right)$. The operating constraints provided the upper and lower search limits of the control settings to be optimized. A supervisor was used to provide the final control settings for the real process based on the compromise of the control stability and energy savings according to the rules defined. For each given working condition, a set of optimal control settings will be identified by the GA optimizer and the predicted cost will be compared to the cost related to the last control settings. If the difference between the two sets of costs is larger than $1.0 \%$, the control settings identified by the GA optimizer will be used to update the last settings. Otherwise, the control settings will remain unchanged.

The detailed prediction process for a GA trail and the interconnections among the performance models under different operation modes are also illustrated in Fig. 2. The water tank recharge mode is used throughout the year. When the operation condition meets the requirement for the water tank recharge, the PVT water pump will be switched on and the power consumption of the PVT water pump $\left(W_{\text {pu.pvt }}\right)$ and the electricity generation of the PVT collectors $(E)$ will be predicted by the performance models under the trail setting of the circulating water mass flow rate $\left(M_{p v t}\right)$. Otherwise, only the electricity generation is predicted. The GSHP for the space cooling mode is only activated during the cooling period and the power consumptions of the heat pump $\left(W_{H P}\right)$, the load side circulation water pump $\left(W_{\text {pu.l }}\right)$ and the source side circulation water pump $\left(W_{\text {pu.s }}\right)$ are predicted based on the trail settings of the 
heat pump load side supply water temperature set-point $\left(T_{l, i n, s e t}\right)$ and the source side supply water temperature set-point $\left(T_{s, i n, s e t}\right)$. The ground recharge mode is only activated during the transition period, during which it was assumed that there is no heating or cooling requirement of the house. The thermal energy to be recharged into the ground $\left(Q_{g r}\right)$ and the power consumption of the source side water pump $\left(W_{\text {pu.s }}\right)$ are predicted based on the inlet water temperature of the GHEs and the trail settings of the ground recharge circulating water mass flow rate $\left(M_{g r}\right)$. During the heating period, the strategy will first determine to use the PVT or GSHP for space heating based on the current online measurements. If the PVT is used for space heating, no control setting needs to be optimized and the only output from the performance model is the power consumption of the load side circulation water pump $\left(W_{p u . l}\right)$. If the GSHP is used for space heating, the prediction process is the same as that of the GSHP for space cooling mode, but different operating constraints will be applied.

\subsection{Description of the cost function, GA fitness function and operating constraints}

As the components in the hybrid GSHP-PVT system interact with each other, the reduction in the power consumption of one component may result in the increase of the power consumption of the other components with respect to the change of control settings [20]. Therefore, the control optimization aims to search for the most energy efficient control settings that can minimize the system energy consumption or maximize the coefficient of performance (COP) under different operation modes. The objective function under the GSHP for space cooling and heating modes can be mathematically expressed in Eq. (1), and those under the water tank recharge and ground recharge modes can be expressed in Eq. (2). Since the instantaneous electricity generation of the PVT collector might be greater than the total power consumption of the system, but the fitness function used in this GA should be nonnegative, the GA fitness function associated with Eq. (1) is therefore defined as in Eq. (3). As the GA used in this study intends to search for the minimum values while the optimization 
objective function defined in Eq. (2) aims to maximize the overall COP, the GA fitness function of Eq. (2) is transformed into Eq. (4).

$$
\begin{aligned}
& J\left(T_{s e t}\right)=\min W_{t o t}=\min \left(W_{H P}+W_{p u, s}+W_{p u, l}+W_{p u, p v t}-E\right) \\
& J\left(m_{s e t}\right)=\max C O P=Q_{g a} / W_{p u} \\
& f_{1}=J\left(T_{s e t}\right)+\mathrm{K} \\
& f_{2}=\frac{1}{J\left(m_{s e t}\right)}
\end{aligned}
$$

where $J$ is the cost function, $f$ is the fitness function, $W$ is the power consumption, $E$ is the electricity generation of the PVT collector, $K$ is a constant that is used to keep the values of the GA fitness function positive, and the subscripts tot, $H P, p u, s, l$ and ga represent total, heat pump, pump, source, load and energy gain, respectively.

To ensure the proper operation of the GSHP-PVT system, a set of system operating constraints was considered. The operation frequencies of the variable speed pumps were constrained between $20 \mathrm{~Hz}$ and $50 \mathrm{~Hz}$. Considering the operation stability and the actual heat transfer capability of the heat pump unit, the heat pump load side supply water temperature set-point was constrained between $5^{\circ} \mathrm{C}$ and $12^{\circ} \mathrm{C}$ under the cooling condition and between $35^{\circ} \mathrm{C}$ and $50^{\circ} \mathrm{C}$ under the heating condition. Taking into account the ground temperature on site and the actual heat transfer characteristics of vertical GHEs, the heat pump source side supply water temperature set-point was constrained between $20^{\circ} \mathrm{C}$ to $35^{\circ} \mathrm{C}$ under the cooling condition and between $6^{\circ} \mathrm{C}$ to $16^{\circ} \mathrm{C}$ under the heating condition.

\subsection{Description of adaptive performance models and model parameter tuning techniques}

The models used in this study were semi-physical models, in which the model parameters were tuned and updated by using the latest operation data and the RLS estimation technique. As the model parameters were continuously updated using the new dataset, the reliability of the models can be guaranteed. The details of the models used are presented as follows. 


\subsubsection{PVT model}

The PVT model used was established based on the mathematical model presented by Fudholi et al. [33], in which the instantaneous thermal efficiency and electrical efficiency of the PVT collector are computed using Eq. (5) and Eq. (6), respectively. The useful heat gain and electricity generation of the PVT collector can be calculated using Eq. (7) and Eq. (8), respectively. The outlet water temperature from the PVT can be calculated using Eq. (9). To identify the three model parameters $\left(a_{1}, a_{2}, a_{3}\right)$, both thermal and electrical efficiencies of the PVT collector need to be calculated based on the measured inlet and outlet water temperatures and the water flow rate, as well as the measured electricity generation.

$$
\begin{aligned}
& \eta_{t h}=a_{1} F_{R, r}(\tau \alpha)_{P V}-a_{2} U_{L, r} F_{R, r}\left(\frac{\mathrm{T}_{i n}-\mathrm{T}_{a m b}}{G_{t}}\right) \\
& \eta_{p v}=\eta_{r}\left(1-a_{3} \varphi\left(\mathrm{T}_{c}-\mathrm{T}_{r}\right)\right) \\
& Q_{u}=\eta_{t h} A_{p v t} G_{t} \\
& E=G t \cdot \eta_{p v} \cdot A_{p v t} \cdot(\tau \alpha)_{P V} \\
& T_{\text {out }}=\frac{Q_{u}}{M_{p v t} \cdot C_{p}}+T_{\text {in }}
\end{aligned}
$$

where $a_{1}-a_{3}$ are the model parameters to be identified, $F_{R, r}$ and $U_{L, r}$ are the heat removal efficiency factor and the overall loss coefficient at the reference condition respectively [33], $(\tau \alpha)_{P V}$ is the product of the transmittance and absorptance of the PV cell, $\eta$ is the efficiency, $\varphi$ is the temperature coefficient, $T$ is the temperature, $Q_{u}$ is the useful heat gain, $E$ is the electricity generation, $A_{p v t}$ is the area of the PVT collector, $G_{t}$ is the incident solar radiation on the PVT collector, $M_{p v t}$ is the circulating water flow rate through the PVT collector, $C_{p}$ is the specific heat of the circulating water, and the subscripts th, $p v$, in, amb, $c, r$ and out represent thermal, photovoltaic, inlet, ambient, cell, reference and outlet, respectively. 


\subsubsection{Water-to-water heat pump model}

The water-to-water heat pump model used was a simplified curve-fitting model developed by Tang [34]. Given the heat pump load side return water temperature and water flow rate, and the source side return water temperature and water flow rate, the model can estimate the required power consumption of the water-to-water heat pump by using Eq. (10). To identify the parameters $b_{0}-b_{4}$, the power consumption of the water-to-water heat pump from the measurements is required.

$$
\frac{W}{W_{r}}=b_{0}+b_{1}\left[\frac{T_{l, \text { out }}}{T_{l, \text { out }, r}}\right]+b_{2}\left[\frac{T_{s, \text { out }}}{T_{s, \text { out }, r}}\right]+b_{3}\left[\frac{m_{l}}{m_{l, r}}\right]+b_{4}\left[\frac{m_{s}}{m_{s, r}}\right]
$$

where $W$ is the power consumption, $T$ is the temperature, $m$ is the water flow rate, and $b_{0}-b_{4}$ are the model parameters to be identified.

\subsubsection{GHE model}

The simplified GHE model used was established based on the heat transfer theory [35]. Under a given inlet water temperature, water flow rate of vertical GHEs and borehole wall temperature, this model can predict the outlet water temperature of the GHEs by using Eq. (11) and Eq. (12). Since temperature sensors may not be installed in many practical projects to measure the borehole wall temperature, a duct ground heat storage model (DST) proposed by Hellstrom [36], as expressed in Eq. (13), was used to estimate the borehole wall temperature. The measured outlet water temperature and water flow rate from the GHEs, and the borehole wall temperature are required to identify and update the model parameter $\alpha$.

$$
\begin{gathered}
Q_{g r}=M_{g} C_{p}\left(T_{g, \text { in }}-T_{g, \text { out }}\right) \\
Q_{g r}=\alpha K_{b, d} N L_{b}\left(\frac{T_{g, \text { in }}+T_{g, \text { out }}}{2}-T_{b}\right) \\
T_{b}=T_{o}+\frac{q_{\text {cond }}}{2 \pi K_{\text {so }}}\left\{\frac{r_{o}^{2}}{r_{o}^{2}-r_{b}^{2}} \cdot\left[\ln \left(\frac{r_{o}}{r_{b}}\right)-\frac{1}{2}+\frac{r_{b}^{2}}{2 r_{o}^{2}}\right]\right\}
\end{gathered}
$$

where $K_{b, d}$ is the borehole thermal conductivity under the design working condition, $L$ is the 
depth, $N$ is the number of boreholes, $\alpha$ is the model parameter to be identified, $M_{g}$ is the circulating water flow rate through GHEs, $C_{p}$ is the specific heat of water, $q_{\text {cond }}$ is the heat transfer rate per unit length of the heat exchanger, $r$ is the radius, $K$ is the thermal conductivity, and the subscripts $g r, g, b$, so and $o$ represent ground recharge, GHE, borehole, soil and outer ground cylinder, respectively.

\subsubsection{Global AHU coil model}

The fictitious global AHU coil model developed by Wang and Jin [23] was used to predict the required water flow rate and the outlet water temperature from the AHU coil. The total heat transfer rates on the water side and air side were computed using Eqs. (14) and (15), respectively. The water side and air side heat transfer coefficients were calculated using Eqs. (16) and (17), respectively. To identify the model parameters of $\gamma_{w}, \phi_{w}, \gamma_{a}$ and $\phi_{a}$, both the heat transfer coefficients in the water side and air side need to be calculated based on the inlet and outlet air and water states of the coil.

$$
\begin{aligned}
& Q_{\text {tot }}=U A_{w}\left(T_{s}-T_{w, i n}\right) \\
& Q_{\text {tot }}=U A_{a}\left(h_{a, i n}-h_{s}\right) \\
& U A_{w}=\gamma_{w}\left(M_{w}\right)^{\phi_{w}} \\
& U A_{a}=\gamma_{a}\left(M_{a}\right)^{\phi_{a}}
\end{aligned}
$$

where $U A$ is the heat transfer coefficient, $M$ is the flow rate, $Q$ is the heat transfer rate, $T_{s}$ is the equivalent coil surface temperature, $h$ is the enthalpy, $h_{s}$ is the saturated air enthalpy at the temperature $T_{s}$, and the subscripts $w$ and $a$ represent water and air, respectively.

\subsubsection{Immersed heat exchanger model}

The simplified immersed heat exchanger model developed by Cadafalch et al. [37] was used to predict the outlet water temperature based on the inlet water temperature and water flow rate, and the water temperature in the water tank. In this model, the total heat transfer 
rate from the immersed heat exchangers to the water tank can be computed by using Eqs. (18) and (19). The overall heat transfer coefficient of each heat exchanger was computed using Eq. (20). There are three parameters $\left(c_{0}-c_{2}\right)$ in this model. To identify these parameters, the heat transfer coefficient needs to be calculated based on the measured inlet and outlet water temperatures and the circulating water flow rate of the immersed heat exchanger, as well as the measured water temperature in the tank. It is worthwhile to note that the water temperature in the tank was assumed to be constant during each sampling interval.

$$
\begin{aligned}
Q_{h x} & =\sum_{i=1}^{n} U A_{h x}^{i}\left(\frac{T_{h x, \text { in }}^{i}+T_{h x, \text { out }}^{i}}{2}-T_{T K}\right) \\
Q_{h x} & =\sum_{i=1}^{n} M_{h x}^{i} C_{p}^{i}\left(T_{h x, \text { in }}^{i}-T_{h x, \text { out }}^{i}\right) \\
U A_{h x} & =c_{0}+c_{1} M_{h x}+c_{2} M_{h x}^{2}
\end{aligned}
$$

where $n$ is the number of the immersed heat exchangers in the tank, $U A$ is the overall heat transfer coefficient, $C_{p}$ is the specific heat, and the subscripts $h x$ and $T K$ represent immersed heat exchanger and tank, respectively.

\subsubsection{Water pump models}

The power input of the water pump is modelled using Eq. (21) [20]. Since the power consumption $\left(W_{p u}\right)$ and water flow rate $\left(M_{p u}\right)$ are measured at each time step, the parameter ( $\beta$ ) can be estimated and updated directly by using Eq. (22) at each sampling time.

$$
\begin{gathered}
W_{p u}=\beta M_{p u}^{3} \\
\beta^{k}=\frac{W_{p u}^{k}}{\left(M_{p u}^{k}\right)^{3}}
\end{gathered}
$$

\subsubsection{Recursive least squares estimation with exponential forgetting}

The adaptive models used in this study were linear in the parameters directly or linear in the parameters after through the logarithm transformation. To ensure reliable estimation of 
these models under various working conditions, the recursive least squares (RLS) estimation technique with exponential forgetting [29], as shown in Eq. (23), was used to update the model parameters. In the RLS estimation, the unknown parameters of a linear model were determined by minimizing the sum of the squares of the difference between the actual observations and the computed values. Exponential forgetting is an approach to discarding more remote data exponentially, which is realized by considering a forgetting factor (i.e. $\lambda$ in Eq. (23)) that gives more weight to the most recent data [20].

$$
V(\theta, t)=\frac{1}{2} \sum_{i=1}^{t} \lambda^{t-i}\left(y(i)-x^{T}(i) \theta\right)^{2}
$$

where $V$ is the loss function, $y$ is the observed variable, $\theta$ is the parameter to be determined, $x$ is the regression variable and $\lambda$ is the forgetting factor $(0<\lambda \leq 1)$.

\section{Performance test and results}

\subsection{Set up of the tests}

In order to test the performance of the proposed control strategy, a virtual simulation system representing the hybrid GSHP-PVT system under study was developed using TRNSYS. In the virtual system, a dynamic PVT model used in an earlier study was utilized [28], and the other major component models used were the standard models provided in the TRNSYS library. The details about the virtual simulation system and the component models used can be found in the previous study [28] and they were not presented herein. It is worthwhile to note that in this performance test, the virtual simulation system was used to mimic the real system to generate the "real-time” operation data. In practical applications, these adaptive performance models will be continuously tuned in the same way at each control time interval but using the latest performance data from the measurements obtained from the real systems.

The building concerned was a two-storey house with a floor area of $248 \mathrm{~m}^{2}$ under 
Melbourne weather conditions. During the test, the water tank recharge mode was switched on when the PVT mean plate temperature was $8{ }^{\circ} \mathrm{C}$ higher than the water temperature in the water tank, and was switched off when the temperature difference between the PVT plate and the water tank was less than $2{ }^{\circ} \mathrm{C}$ [13] to ensure a relatively high heat transfer efficiency of the PVT collector. The ground recharge was implemented between 10:00 and 17:00 during the transition period when the water temperature in the tank was over $30{ }^{\circ} \mathrm{C}$. The amount of the thermal energy to be recharged into the ground was estimated based on the predetermined annual heat extraction and heat rejection from the GSHP system through simulations. Once the thermal energy transferred to the ground can maintain the annual ground thermal balance, the ground recharge was then completed, and the heat energy generated from the PVT collector was used for DHW only. The space heating/cooling mode was used when there was a heating or cooling demand from 17:00 to 10:00 of the next day on the weekdays and all day on the weekends when the house was occupied. Under the space heating mode, the PVT for space heating was implemented when the water temperature in the water tank was over $40{ }^{\circ} \mathrm{C}$. Otherwise, the GSHP for space heating model was applied. Under the space cooling mode, only the GSHP was used. For stable control and operation, a minimal time interval was introduced to avoid frequent ON/OFF of the major system components. The DHW consumption of the building was set between $7: 00$ to $10: 00$ and 17:30 to $21: 30$ with a flow rate of $16 \mathrm{~L} / \mathrm{h}$ throughout the year [38]. The electric water heater was used to heat the water from the water tank when there was a DHW demand and the water temperature from the tank was lower than the required temperature.

The performance of the proposed model-based control strategy (namely Strategy A in the following analysis) was evaluated by comparing with that of a conventional control strategy (namely Strategy B in the following analysis). In the conventional control strategy, the water tank recharge flow rate and ground recharge water flow rate were set to be constant with the 
pump operating frequency of $50 \mathrm{~Hz}$. Under the GSHP for space cooling/heating mode, a twostage control was used to regulate the operating speed of the water pumps. The operating frequencies of the variable speed pumps at the heat pump source side and load side were set as $25 \mathrm{~Hz}$ when the building load was less than $50 \%$ of the design building load and they were increased to $50 \mathrm{~Hz}$ when the building load was greater than $50 \%$ of the design building load. The operation mode of the system in the conventional strategy was determined using the same rules as those used in the proposed control strategy.

To calculate the air flow rate and inlet air states of the AHU, a series of assumptions were used. In the cooling condition, the room design air temperature was set as $24{ }^{\circ} \mathrm{C}$ [39]. The air temperature leaving the AHU was controlled at $13{ }^{\circ} \mathrm{C}[20]$. In the heating condition, the room design air temperature was set to $21{ }^{\circ} \mathrm{C}$ [39] and the air temperature leaving the AHU was controlled at $32{ }^{\circ} \mathrm{C}$ [40]. The minimum ratio of the fresh air to the total supply air was considered to be $15 \%$. During the tests, the simulation time step of the virtual simulation system, the sampling interval for the model parameter identification and the identification of the optimal control settings in Strategy A were 600s.

Since the accuracy of the performance models directly affects the performance of the model-based control strategy, the outputs of the major adaptive performance models presented in Section 3.3 were first validated using the simulation data generated from the virtual simulation system. The simulation data of five consecutive days in the transition period between heating and cooling seasons were selected to demonstrate the prediction performance of the PVT collector, the GHE and the immersed heat exchanger models. The simulation data of five consecutive days in the cooling period and five consecutive days in the heating period were selected to demonstrate the prediction performance of the water-to-water heat pump model and the AHU model under cooling and heating conditions, respectively. In order to further demonstrate the effectiveness of the major adaptive performance models, one 
day experimental testing data obtained from a GSHP system [7] and one day performance testing data of a water-based PVT collector reported by Ibrahim et al. [41] were further used to validate the PVT model, water-to-water heat pump model and ground heat exchangers models.

In order to evaluate the performance of the optimal control strategy, three tests were designed under the cooling period, transition period and heating period, respectively. The cooling period for the specific Australian climate was assumed from the beginning of December to the end of March next year, the heating period was from the beginning of May to the end of October, and the transition period was the whole April and November. Each test was carried out based on the same five consecutive days that were used for the model validation. Fig. 3 presents the outdoor air dry-bulb and wet-bulb temperatures, the building cooling/heating load profiles, and the incident solar radiation during the selected five days in the cooling, heating and transition periods, in which the building cooling and heating loads were simulated using DesignBuilder based on the design data and weather data in the typical year of Melbourne.

\subsection{Validation of the performance models}

Fig. 4 presents the estimated and 'measured' thermal energy gain and electricity generation of the PVT collector. It is worthwhile to note here that the estimated values were calculated by the simplified PVT model, while the 'measured' values were calculated using the performance data generated by the virtual simulation system. It can be seen that both the estimated and 'measured' thermal energy gains and electricity generations varied with the variation of the incident solar radiation during the day and they both were close to each other. It can also be observed that the thermal energy gain was much higher than the electricity generation, especially when the incident solar radiation was high, indicating that the waterbased PVT collectors had a comparatively higher thermal efficiency than the electric 
efficiency.

Fig. 5 and Fig. 6 present the validation results of the GHE model and the immersed heat exchanger model respectively, based on the performance data generated by the virtual simulation system. It can be observed that the estimated outlet water temperatures of the GHE and immersed heat exchangers agreed well with the 'measured' values, indicating that both models can provide acceptable performance prediction.

Fig. 7 shows the estimated and the 'measured' overall heat transfer coefficients (i.e. UA values) at the air side and water side of the AHU coil based on the performance data generated by the virtual simulation system. It can be seen that the estimated UA values varied closely to the variation of the 'measured' values. However, during the peak cooling and heating period, the estimated water side UA values were slightly deviated from the 'measured' values, due to the delay in the response of the RLS estimator to the change of the system dynamics. It can also be observed that the UA values at the water side were higher than those at the air side under both cooling and heating conditions, since water has a better heat transfer performance than air.

Fig. 8 presents the comparison between the predicted and 'measured' instantaneous power consumption of the water-to-water heat pump under the cooling and heating conditions. It can be observed that the estimated power consumption agreed well with the 'measured' value obtained from the virtual simulation system during the whole operation period.

Fig. 9 illustrates the validation of the PVT model, water-to-water heat pump model and ground heat exchanger model using the experimental data described in Section 4.2. The model parameters were continuously updated at each time step using the new dataset from the testing data and the RLS estimation technique, and the model prediction results were compared with the measured values. It can be observed that the estimated values also agreed well with the measured values. The model validation results presented above demonstrated 
that the performance models using the RLS estimation technique with exponential forgetting can provide reliable performance prediction under varying working conditions.

It is worthwhile to note that, in order to initialize the RLS algorithm and to reduce the prediction error, the estimated parameters using the RLS estimators at the starting phase of the system were not used to update the model parameters. The model parameters were continuously updated after a few time steps when the system operation became stable.

\subsection{Test and evaluation of the control strategy}

In this section, the performance of the GSHP-PVT system using the two control strategies (Strategy A and Strategy B) were evaluated and compared during the cooling, heating and transition test periods, respectively.

\subsubsection{Performance evaluation during the cooling test period}

The five consecutive days during the cooling period, as presented in Fig. 3a), were used to evaluate the performance of the two control strategies. The operation modes of the GSHPPVT system during the cooling period included the water tank recharge mode and GSHP for space cooling mode. Fig. 10 presents the temperature set-points identified under the GSHP for space cooling mode and the recharge water flow rate identified under the water tank recharge mode by using the two control strategies. It can be observed that the load side supply water temperature searched by Strategy A was apparently different from that identified by Strategy B (Fig 10a). The source side supply water temperatures searched by using the two control strategies were relatively close to each other. It can also be seen that the water tank recharge flow rate identified by Strategy A generally increased with the increase of the solar radiation (Fig. 10b), since a higher COP for the water tank recharge can be achieved with a larger flow rate under a higher solar radiation, while that in Strategy B remained constant.

\subsubsection{Performance evaluation during the heating test period}

The operation modes of the GSHP-PVT system during the heating period included the 
water tank recharge mode, GSHP for space heating mode and PVT for space heating mode. The two control strategies were used to search for the load side and source side supply water temperature set-points under the GSHP for space heating mode, and search for the water flow rate set-points under the water tank recharge mode. When using PVT for space heating, there was no optimization carried out and the water flow rate was determined based on the building heating load and the outlet water temperature from the water tank. Fig. 11 presents the searched results of the temperature set-points and the water tank recharge water flow rates identified by using the two control strategies during the heating test period presented in Fig. 3b). It can be observed that under both strategies, the PVT for space heating mode was only switched on during the very short time periods from 17:00 to 18:20 in the third day, and from 17:00 to 17:30 in the fourth day (i.e. high load side supply water temperature appeared in Fig. 11 a)). This is because the useful heat generated from the PVT collector was relatively small during the heating period, and it hardly heated the water in the tank up to the required temperature for the PVT space heating. During the GSHP for space heating mode, the load side supply water temperatures identified by using the two strategies apparently deviated from each other, but the source side supply water temperatures identified were relatively close to each other. It can be seen from Fig. 11b) that the circulation water flow rates for the water tank recharge searched by using Strategy A varied with the variation in the solar radiation during the daytime, and those controlled by Strategy B remained constant. The duration of the water tank recharge mode was relatively short in the heating test period, compared with that in the cooling test period, since the low solar radiation intensity in winter made it difficult to meet the requirement of the water tank recharge.

\subsubsection{Performance evaluation during the transition test period}

The operation modes of the GSHP-PVT system during the transition period included the water tank recharge mode and ground recharge mode. In Strategy B, the water tank recharge 
and ground recharge flow rates remained constant at $0.72 \mathrm{~kg} / \mathrm{s}$ and $0.65 \mathrm{~kg} / \mathrm{s}$ respectively when the pumps operated at $50 \mathrm{~Hz}$. In Strategy A, the most energy efficient settings of the water tank recharge and ground recharge flow rates were identified by using the GA optimizer. Fig. 12 presents the water flow rate set-points identified by using Strategy A and the constant flow rates used in Strategy B. It can be observed that the optimal water tank recharge flow rate searched by Strategy A also varied with the variation in the solar radiation during the daytime. The ground recharge flow rate search by Strategy A fluctuated in a narrow range around $0.3 \mathrm{~kg} / \mathrm{s}$. The optimal ground recharge flow rates were closely related to the ground recharge water temperatures. A lower recharge flow rate was more energy efficient (i.e. higher COP for the ground recharge) when a higher ground recharge water temperature was used, and vice versa.

Table 2 summarizes the accumulated electricity consumption and electricity generation of the system during the whole cooling, heating and transition periods within a year by using the control settings identified by the two different control strategies. The performance of the two strategies during each period were evaluated and compared based on the same working conditions. It can be observed that, compared to the conventional control strategy (Strategy B), the system using the proposed model-based control strategy (Strategy A) reduced electricity consumption by $7.8 \%, 7.1 \%$ and $7.5 \%$ and generated $4.4 \%, 6.2 \%$ and $5.1 \%$ more electricity during the whole cooling, heating and transition periods, respectively. These savings were achieved through applying the optimal control strategy only and without adding any additional cost to the system.

The above results demonstrated that the proposed model-based control strategy that considered the interactions among the individual components and system-level characteristics is more energy efficient and cost-effective compared to the conventional control strategy. The adaptive performance models used to formulate the control strategy were relatively simple 
and the model parameters were continuously updated using the new dataset from online measurements to ensure the reliability of the models. With the wide deployment of building management systems, this control optimization strategy and the associated results have a potential to be used to facilitate the development of practical and reliable real-time control strategies for practical applications.

\section{Conclusions}

This paper presented the development and evaluation of a model-based optimal control strategy for a hybrid ground source heat pump system integrated with water-based photovoltaic thermal collectors (GSHP-PVT). In this proposed strategy, the system operation modes were first determined under the giving working condition and a model-based performance optimizer was used to identify the energy efficient control settings. The simplified adaptive performance models were used for performance prediction and the model parameters were continuously updated using the recursive least squares (RLS) estimation technique with exponential forgetting to ensure reliable performance prediction. A genetic algorithm (GA) was used to search for the optimal solution for the optimization problem. The performance of the adaptive models and the proposed control strategy were tested and evaluated based on a virtual simulation system that represented a hybrid GSHP-PVT system in a residential application in Melbourne, Australia. The major adaptive models were also validations using the experimental testing data.

The model validation results showed that the simplified adaptive models combined with the least squares (RLS) estimation technique were able to provide a reliable prediction of the system performance under various working conditions. The test and evaluation of the optimal

control strategy showed that this strategy was able to reduce the system electricity consumption by $7.8 \%, 7.1 \%$ and $7.5 \%$, and increase the electricity generation by $4.4 \%, 6.2 \%$ and 5.1\% during the whole cooling, heating and transition periods respectively, in comparison 
to a conventional control strategy. This method can be potentially adapted to develop online and practical control strategies for stand-alone GSHP and hybrid GSHP-PVT systems.

\section{References}

[1] Chen J, Xia L, Li B, Mmereki D. Simulation and experimental analysis of optimal buried depth of the vertical U-tube ground heat exchanger for a ground-coupled heat pump system. Renew Energ. 2015;73:46-54.

[2] Wang Z, Wang F, Liu J, Ma Z, Han E, Song M. Field test and numerical investigation on the heat transfer characteristics and optimal design of the heat exchangers of a deep borehole ground source heat pump system. Energy Convers Manage. 2017;153:603-15.

[3] Huang S, Ma Z, Cooper P. Optimal design of vertical ground heat exchangers by using entropy generation minimization method and genetic algorithms. Energy Convers Manage. 2014;87:128-37.

[4] Chow TT. A review on photovoltaic/thermal hybrid solar technology. Appl Energ. 2010;87:365-79.

[5] Sundbrandt M. Control of a Ground Source Heat Pump using Hybrid Model Predictive Control [MSc Thesis]: Linkopings University; 2011.

[6] Sivasakthivel T, Murugesan K, Thomas HR. Optimization of operating parameters of ground source heat pump system for space heating and cooling by Taguchi method and utility concept. Appl Energ. 2014;116:76-85.

[7] Xia L, Ma Z, McLauchlan C, Wang S. Experimental investigation and control optimization of a ground source heat pump system. Appl Therm Eng. 2017;127:70-80.

[8] Gao J, Huang G, Xu X. An optimization strategy for the control of small capacity heat pump integrated air-conditioning system. Energy Convers Manage. 2016;119:1-13.

[9] Hu B, Li Y, Mu B, Wang S, Seem JE, Cao F. Extremum seeking control for efficient 
operation of hybrid ground source heat pump system. Renew Energ. 2016;86:332-46.

[10] Ikeda S, Choi W, Ooka R. Optimization method for multiple heat source operation including ground source heat pump considering dynamic variation in ground temperature. Appl Energ. 2017;193:466-78.

[11] Gang W, Wang J. Predictive ANN models of ground heat exchanger for the control of hybrid ground source heat pump systems. Appl Energ. 2013;112:1146-53.

[12] Weeratunge H, Narsilio G, de Hoog J, Dunstall S, Halgamuge S. Model predictive control for a solar assisted ground source heat pump system. Energy. 2018;152:974-84.

[13] Entchev E, Yang L, Ghorab M, Lee E. Performance analysis of a hybrid renewable microgeneration system in load sharing applications. Appl Therm Eng. 2014;71:697-704.

[14] Canelli M, Entchev E, Sasso M, Yang L, Ghorab M. Dynamic simulations of hybrid energy systems in load sharing application. Appl Therm Eng. 2015;78:315-25.

[15] Emmi G, Zarrella A, De Carli M. A heat pump coupled with photovoltaic thermal hybrid solar collectors: A case study of a multi-source energy system. Energy Convers Manage. 2017;151:386-99.

[16] Entchev E, Yang L, Ghorab M, Rosato A, Sibilio S. Energy, economic and environmental performance simulation of a hybrid renewable microgeneration system with neural network predictive control. Alexandria Eng J. 2016.

[17] Putrayudha SA, Kang EC, Evgueniy E, Libing Y, Lee EJ. A study of photovoltaic/thermal (PVT)-ground source heat pump hybrid system by using fuzzy logic control. Appl Therm Eng. 2015;89:578-86.

[18] Ge G, Xiao F, Xu X. Model-based optimal control of a dedicated outdoor air-chilled ceiling system using liquid desiccant and membrane-based total heat recovery. Appl Energ. 2011;88:4180-90.

[19] Afram A, Janabi-Sharifi F. Gray-box modeling and validation of residential HVAC 
system for control system design. Appl Energ. 2015;137:134-50.

[20] Ma Z, Wang S. Supervisory and optimal control of central chiller plants using simplified adaptive models and genetic algorithm. Appl Energ. 2011;88:198-211.

[21] Candanedo J, Dehkordi V, Stylianou M. Model-based predictive control of an ice storage device in a building cooling system. Appl Energ. 2013;111:1032-45.

[22] Nassif N, Moujaes S, Zaheeruddin M. Self-tuning dynamic models of HVAC system components. Energy Build. 2008;40:1709-20.

[23] Wang S, Jin X. Model-based optimal control of VAV air-conditioning system using genetic algorithm. Build Environ. 2000;35:471-87.

[24] Soyguder S, Alli H. Predicting of fan speed for energy saving in HVAC system based on adaptive network based fuzzy inference system. Expert Syst Appl. 2009;36:8631-8.

[25] Yan Y, Zhou J, Lin Y, Yang W, Wang P, Zhang G. Adaptive optimal control model for building cooling and heating sources. Energy Build. 2008;40:1394-401.

[26] Zhao Y, Xie W, Tu X. Performance-based parameter tuning method of model-driven PID control systems. ISA transactions. 2012;51:393-9.

[27] Zhu Y, Jin X, Du Z, Fang X. Online optimal control of variable refrigerant flow and variable air volume combined air conditioning system for energy saving. Appl Therm Eng. 2015;80:87-96.

[28] Xia L, Ma Z, Kokogiannakis G, Wang Z, Wang S. A model-based design optimization strategy for ground source heat pump systems with integrated photovoltaic thermal collectors. Appl Energ. 2018;214:178-90.

[29] Aström KJ, Wittenmark B. Adaptive control: Courier Corporation; 2013.

[30] Kalogirou SA. Optimization of solar systems using artificial neural-networks and genetic algorithms. Appl Energ. 2004;77:383-405.

[31] Fong K, Yuen S, Chow CK, Leung SW. Energy management and design of centralized 
air-conditioning systems through the non-revisiting strategy for heuristic optimization methods. Appl Energ. 2010;87:3494-506.

[32] Ma Z, Wang S. Test and evaluation of energy saving potentials in a complex building central chilling system using genetic algorithm. Build Serv Eng Res Technol. 2011;32:109-26. [33] Fudholi A, Sopian K, Yazdi MH, Ruslan MH, Ibrahim A, Kazem HA. Performance analysis of photovoltaic thermal (PVT) water collectors. Energy Convers Manage. 2014;78:641-51.

[34] Tang CC. Modeling packaged heat pumps in a quasi-steady state energy simulation program: Oklahoma State University; 2005.

[35] Lamarche L, Kajl S, Beauchamp B. A review of methods to evaluate borehole thermal resistances in geothermal heat-pump systems. Geothermics. 2010;39:187-200.

[36] Hellström G. Ground heat storage: thermal analyses of duct storage systems. Sweden: Department of Mathematical Physics, Lund University; 1991.

[37] Cadafalch J, Carbonell D, Consul R, Ruiz R. Modelling of storage tanks with immersed heat exchangers. Solar Energy. 2015;112:154-62.

[38] REMP. Water Heating Data Collection and Analysis. Commonwealth Department of the Environment and Energy; 2012.

[39] ASHRAE Standard 55-2010. Thermal Environmental Conditions for Human Occupancy. ASHRAE. Atlanta USA. 2010.

[40] Kang S-H, Kim H-J, Cho Y-H. A study on the control method of single duct VAV terminal unit through the determination of proper minimum air flow. Energy Build. 2014;69:464-72.

[41] Ibrahim A, Fudholi A, Sopian K, Othman MY, Ruslan MH. Efficiencies and improvement potential of building integrated photovoltaic thermal (BIPVT) system. Energy Convers Manage. 2014;77:527-34. 
Table 1 Operation modes of the GSHP-PVT system

\begin{tabular}{lll}
\hline Mode & Description & Operation period \\
\hline & $\begin{array}{l}\text { Using thermal energy generated from the } \\
\text { PVT collector to recharge the hot water }\end{array}$ & \\
$\begin{array}{l}\text { Water tank } \\
\text { recharge }\end{array}$ & $\begin{array}{l}\text { tank. The thermal energy stored in the } \\
\text { water tank can be used for ground }\end{array}$ & Whole year \\
& recharge, space heating and DHW & \\
\hline $\begin{array}{l}\text { GSHP for space } \\
\text { heating/cooling }\end{array}$ & $\begin{array}{l}\text { Using the GSHP system for space heating } \\
\text { and cooling. }\end{array}$ & $\begin{array}{l}\text { Heating/cooling } \\
\text { period }\end{array}$ \\
\hline $\begin{array}{l}\text { PVT for space } \\
\text { heating }\end{array}$ & $\begin{array}{l}\text { Using thermal energy generated from the } \\
\text { PVT for space heating. }\end{array}$ & Heating period \\
\hline Ground recharge & $\begin{array}{l}\text { Using thermal energy collected from the } \\
\text { PVT to recharge the ground. }\end{array}$ & \multirow{2}{*}{ Transition period } \\
\hline
\end{tabular}

Table 2 Electricity consumption and generation of the GSHP-PVT system when using

\begin{tabular}{cccccc}
\multicolumn{5}{c}{ different control strategies } \\
\hline \multirow{2}{*}{ Time } & Control & $\begin{array}{c}\text { Electricity } \\
\text { consumption } \\
\text { period }\end{array}$ & $\begin{array}{c}\text { Savings } \\
\text { strategy }\end{array}$ & $\begin{array}{c}\text { Electricity } \\
\text { generation } \\
(\mathrm{kWh})\end{array}$ & $\begin{array}{c}\text { increments } \\
\%\end{array}$ \\
\hline \multirow{2}{*}{ Cooling } & Strategy A & 601.7 & $7.8 \%$ & 1218.5 & $4.4 \%$ \\
& Strategy B & 652.9 & - & 1166.7 & - \\
& Strategy A & 2719.9 & $7.1 \%$ & 1369.8 & $6.2 \%$ \\
\multirow{2}{*}{ Teating } & Strategy B & 2926.3 & - & 1289.4 & - \\
& Strategy A & 412.0 & $7.5 \%$ & 493.5 & $5.1 \%$ \\
& Strategy B & 445.3 & - & 469.5 & - \\
\hline
\end{tabular}




\section{Figure captions}

Fig. 1 Schematic of the GSHP-PVT system.

Fig. 2 Overall optimization process of the proposed optimal control strategy.

Fig. 3 Weather data of the selected five consecutive days.

Fig. 4 Comparison between the estimated and measured thermal energy gain and electricity generation of the PVT collector.

Fig. 5 Comparison between the estimated and measured outlet water temperatures of the GHE. Fig. 6 Comparison between the estimated and measured outlet water temperatures of the immersed heat exchangers.

Fig. 7 Comparison between the estimated and measured UA values at the air side and the water side of the AHU coil.

Fig. 8 Comparison between the estimated and measured power consumption of the water-towater heat pump.

Fig. 9 Validation of the adaptive models using the performance data obtained from the experimental tests.

Fig. 10 Temperature and flow rate settings identified by using two control strategies during the cooling period.

Fig. 11 Temperature and flow rate settings identified by using two control strategies during the heating period.

Fig. 12 Flow rate set-points identified by using the two control strategies during the transition test period. 


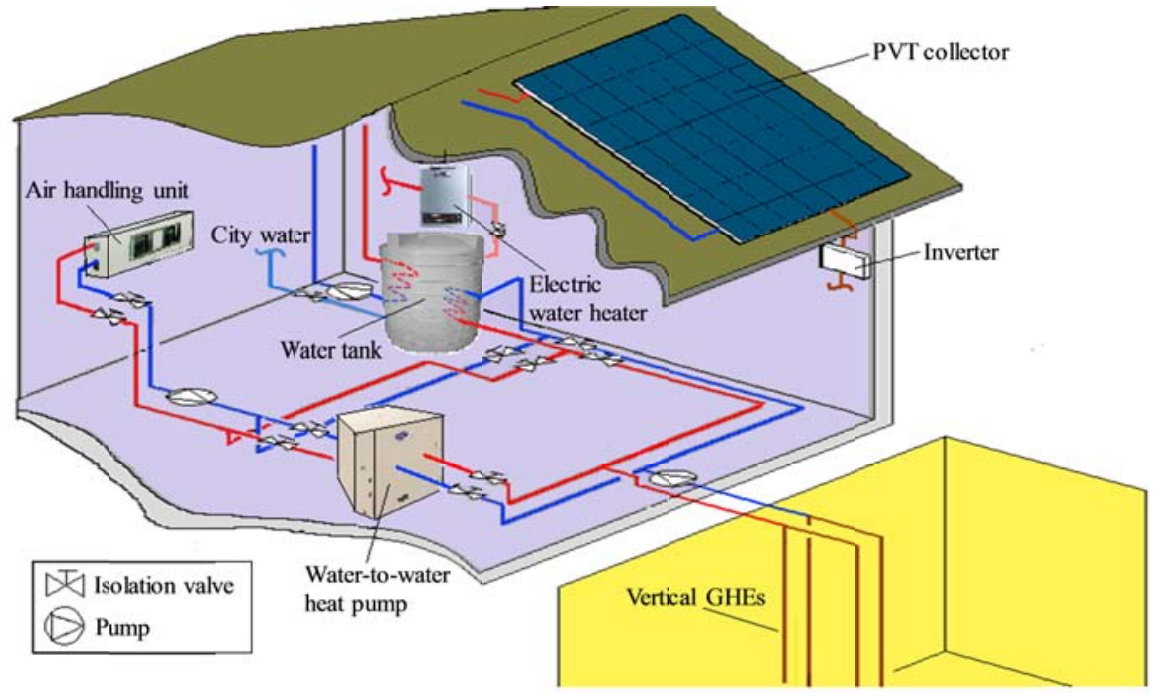

Fig. 1 Schematic of the GSHP-PVT system. 


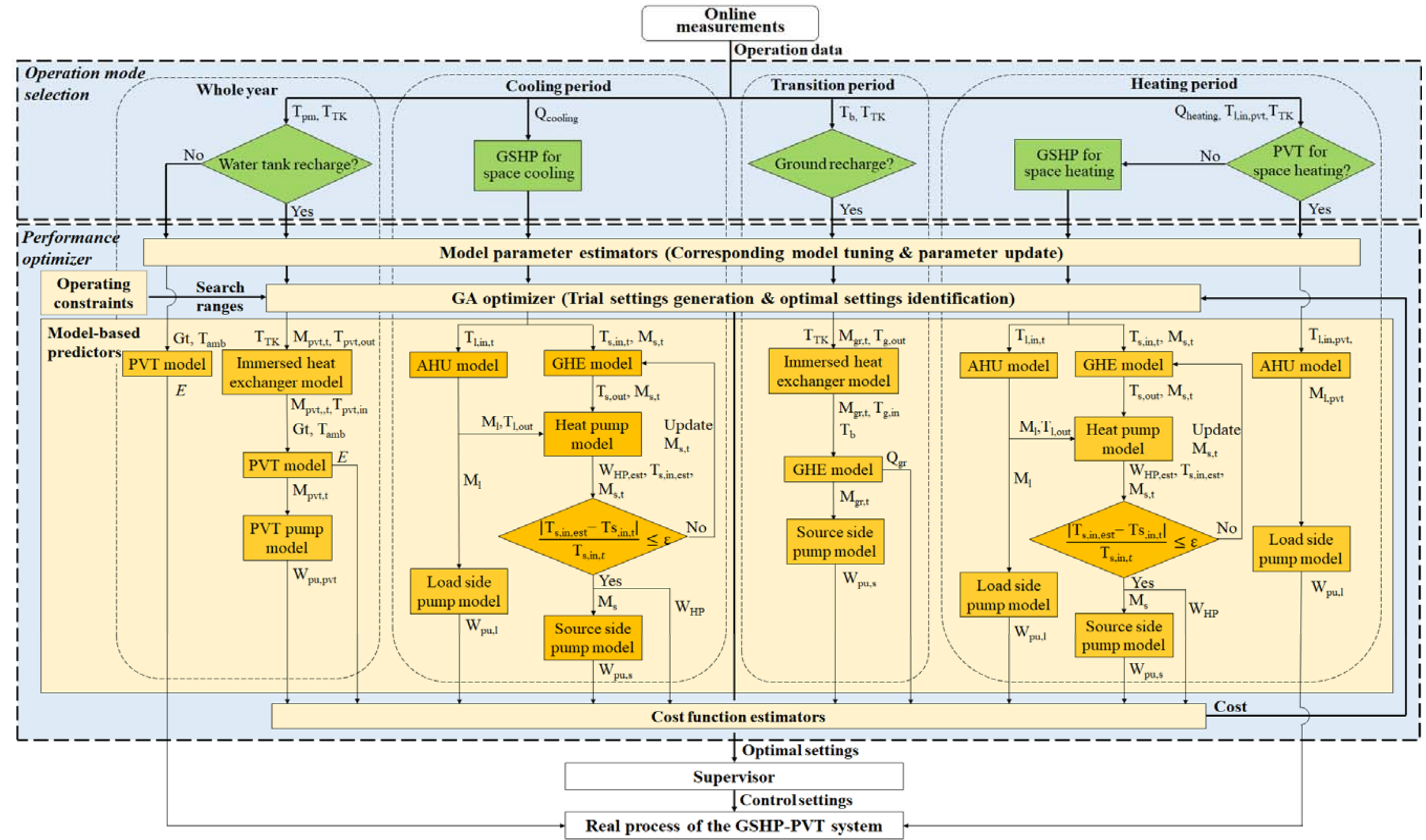

Fig. 2 Overall optimization process of the proposed optimal control strategy. 


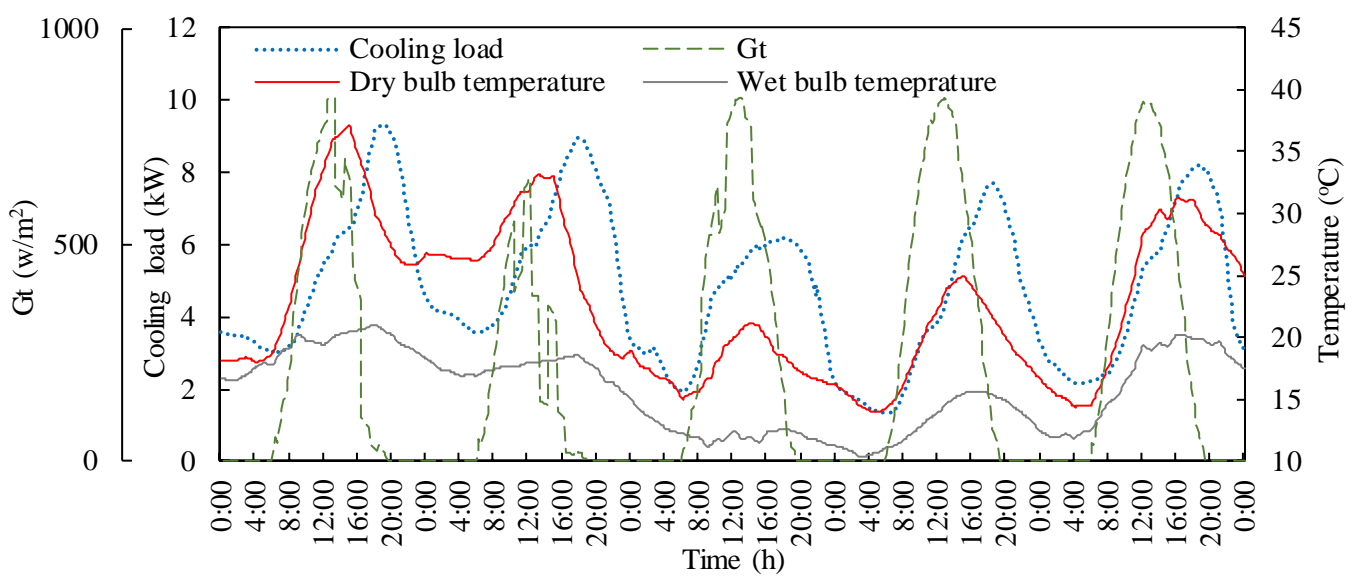

a) cooling period

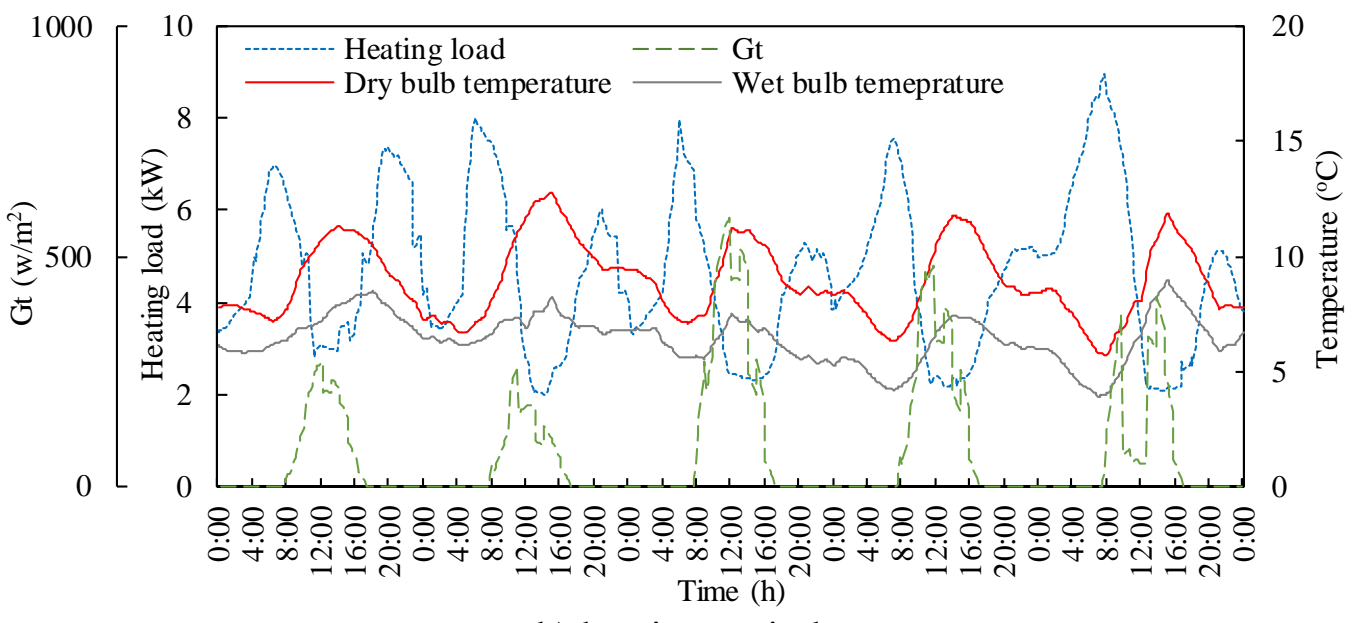

b) heating period

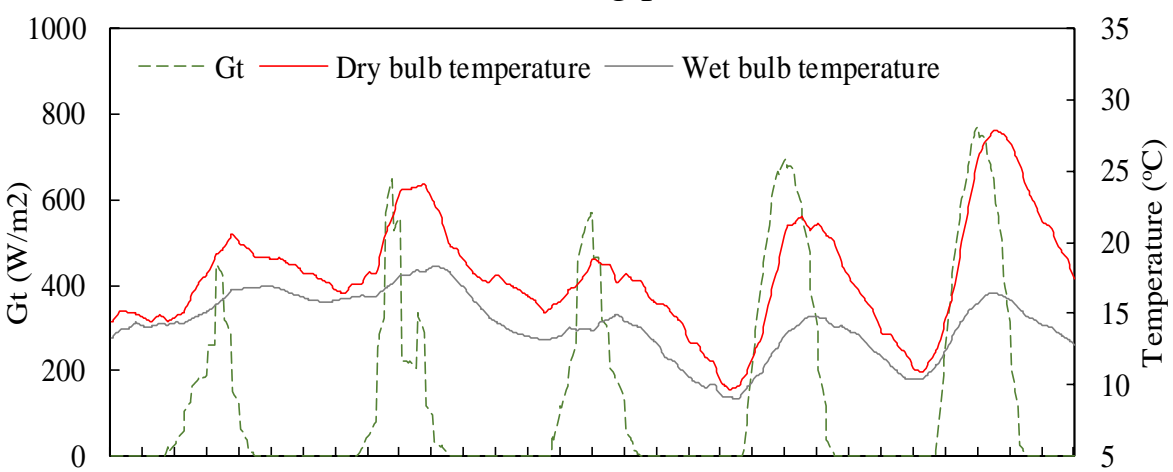

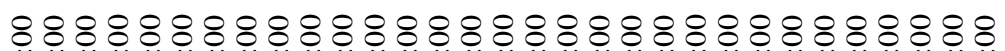

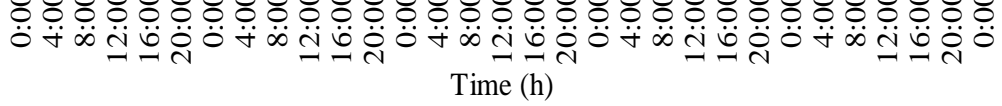

c) Transition period

Fig. 3 Weather data of the selected five consecutive days. 


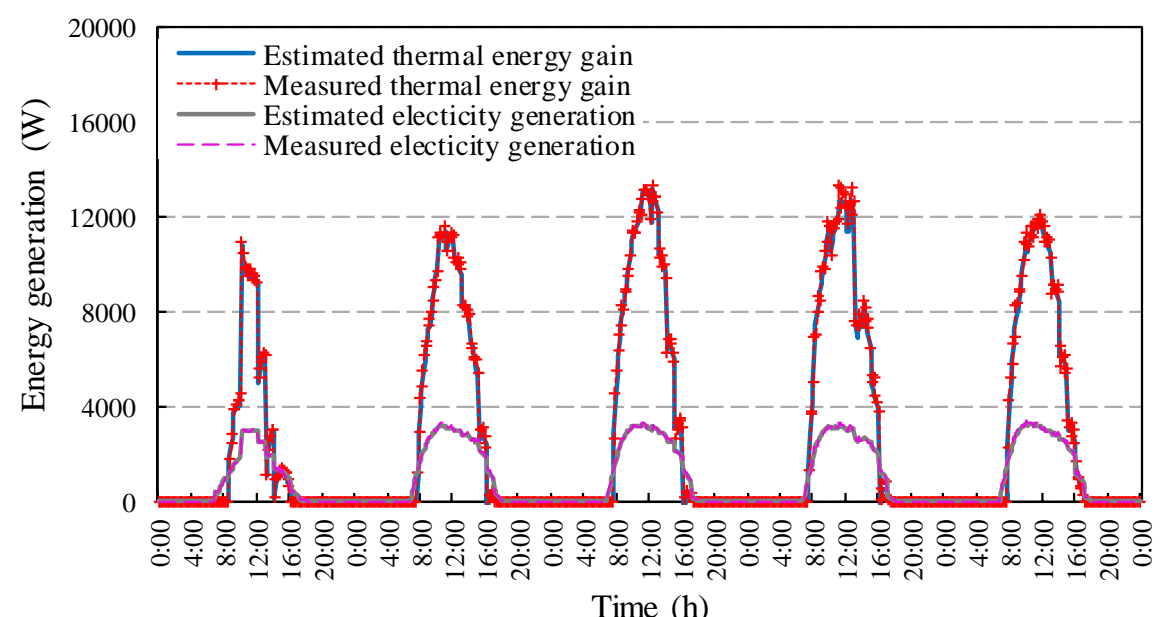

Fig. 4 Comparison between the estimated and measured thermal energy gain and electricity generation of the PVT collector.

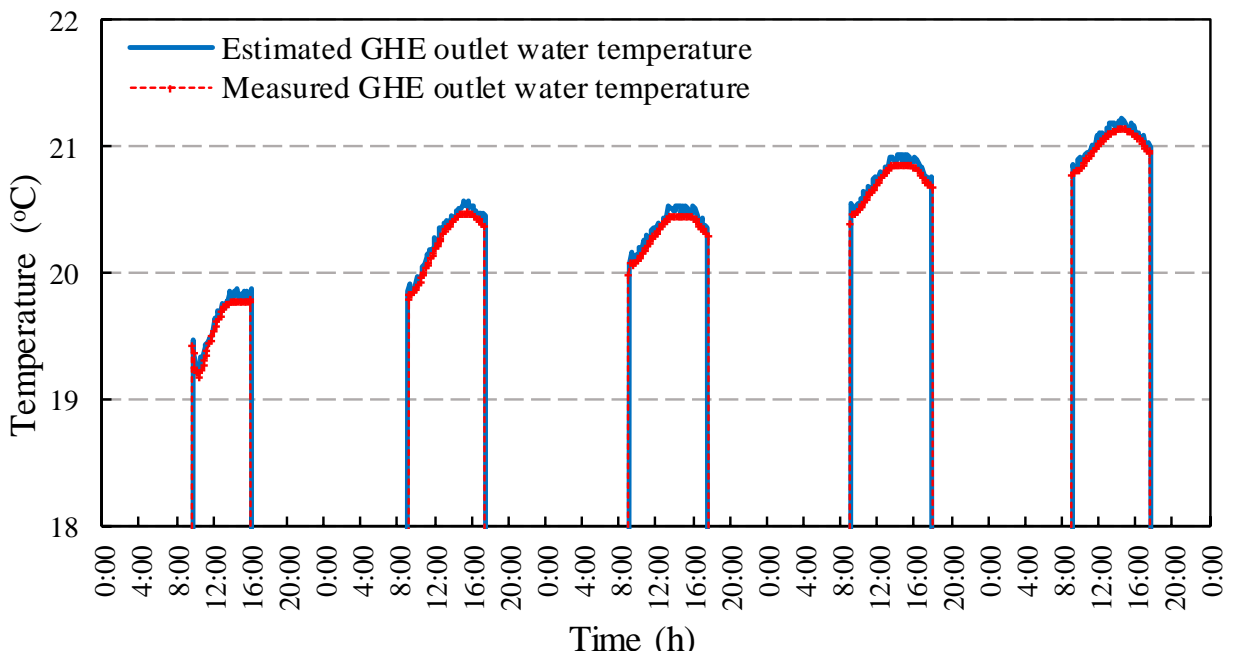

Fig. 5 Comparison between the estimated and measured outlet water temperatures of the GHE.

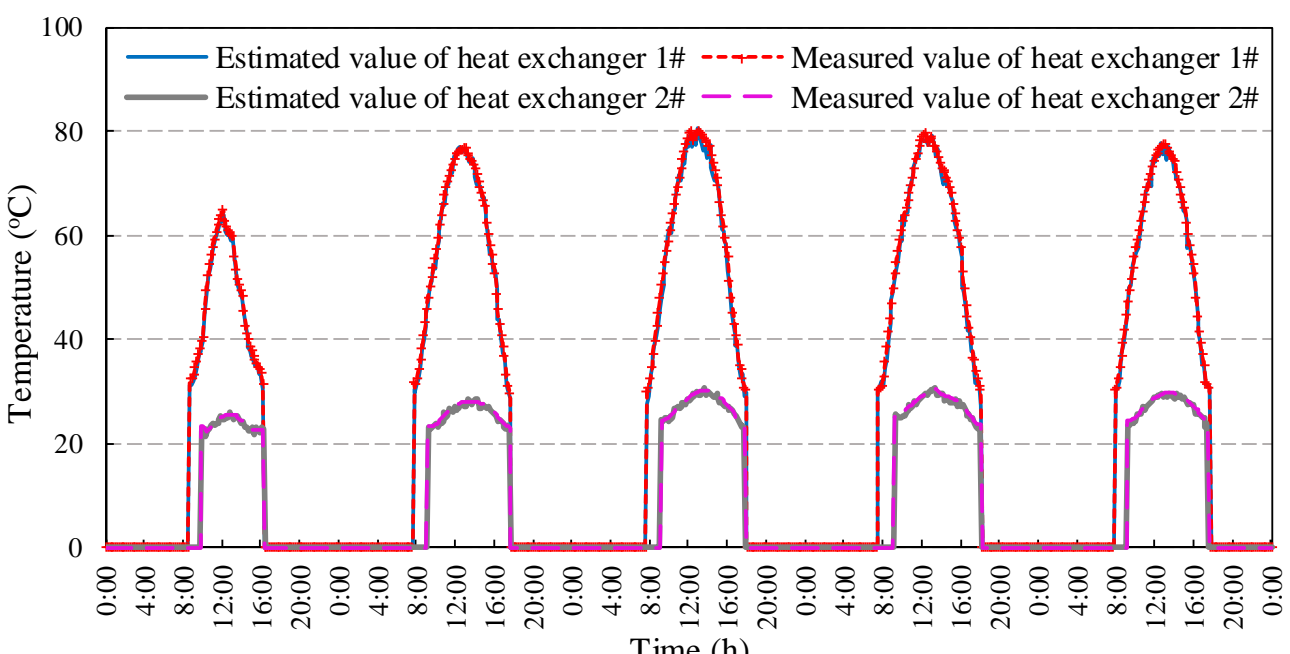

Fig. 6 Comparison between the estimated and measured outlet water temperatures of the immersed heat exchangers. 


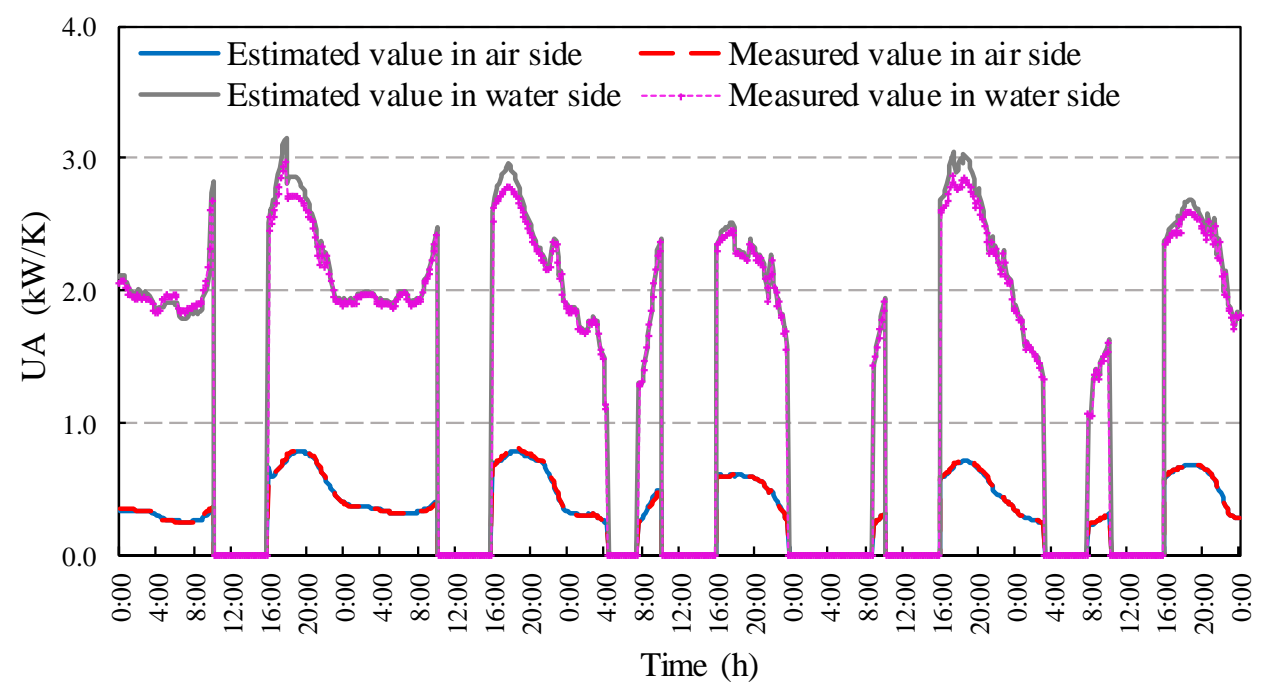

a) Cooling condition

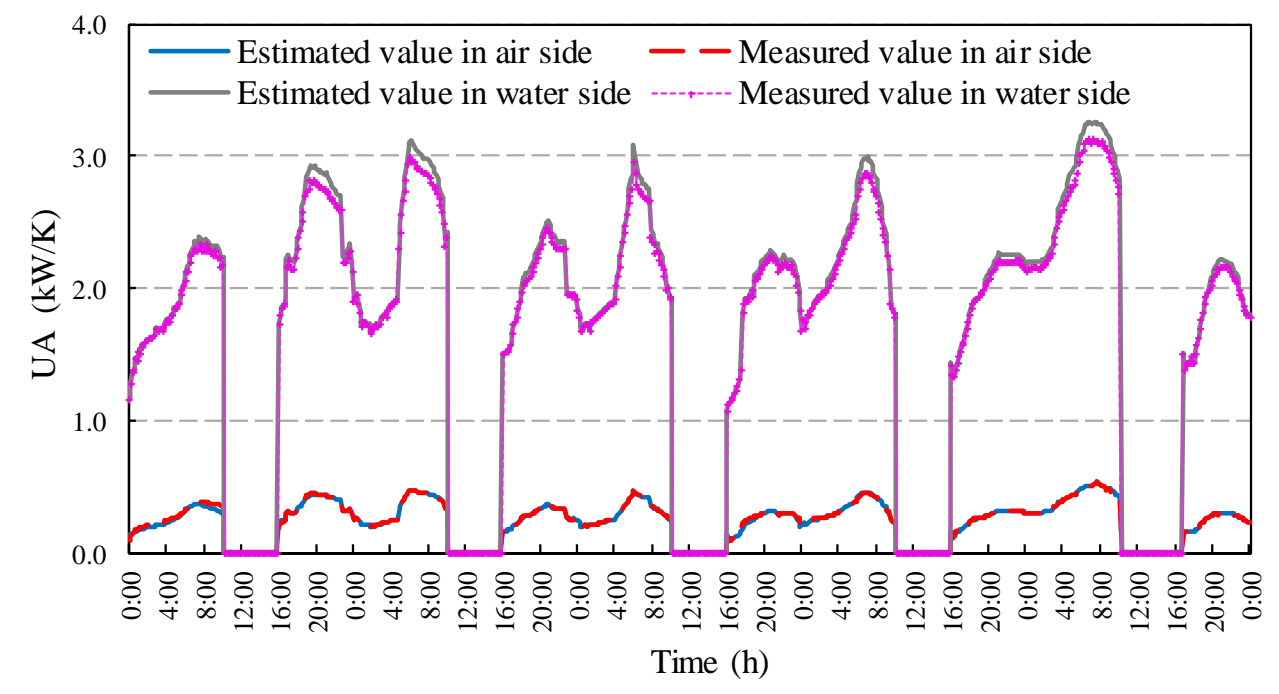

b) Heating condition

Fig. 7 Comparison between the estimated and measured UA values at the air side and the water side of the AHU coil. 


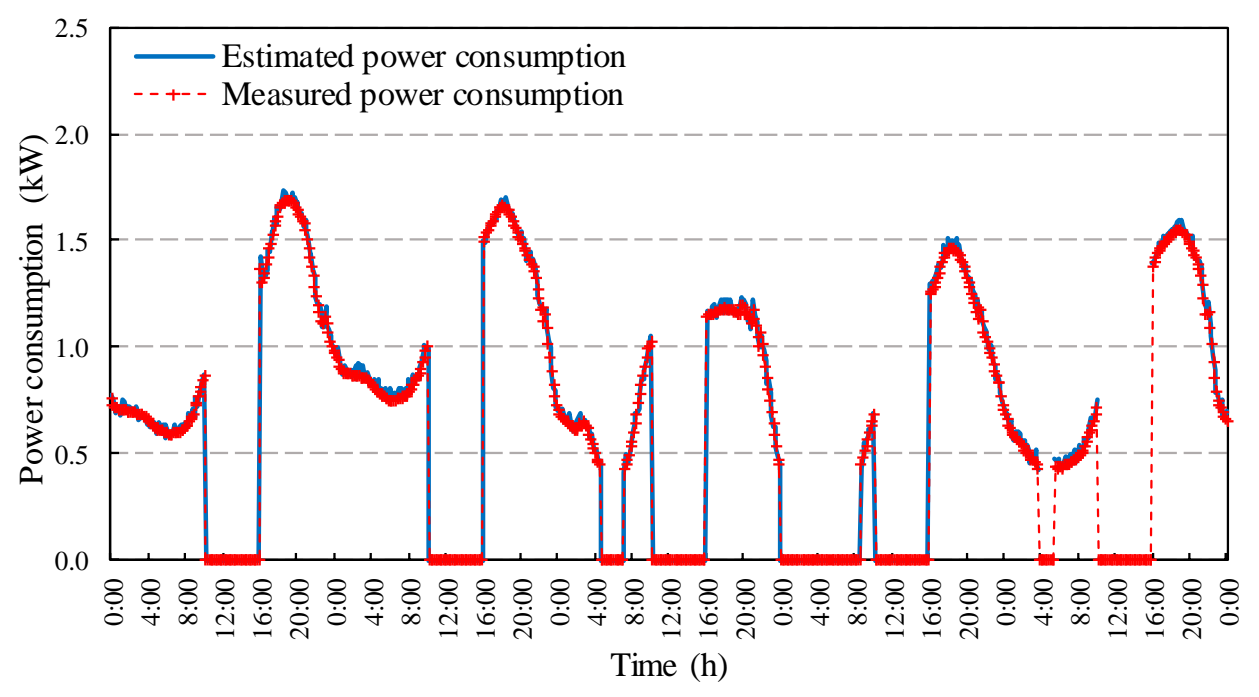

a) Cooling condition

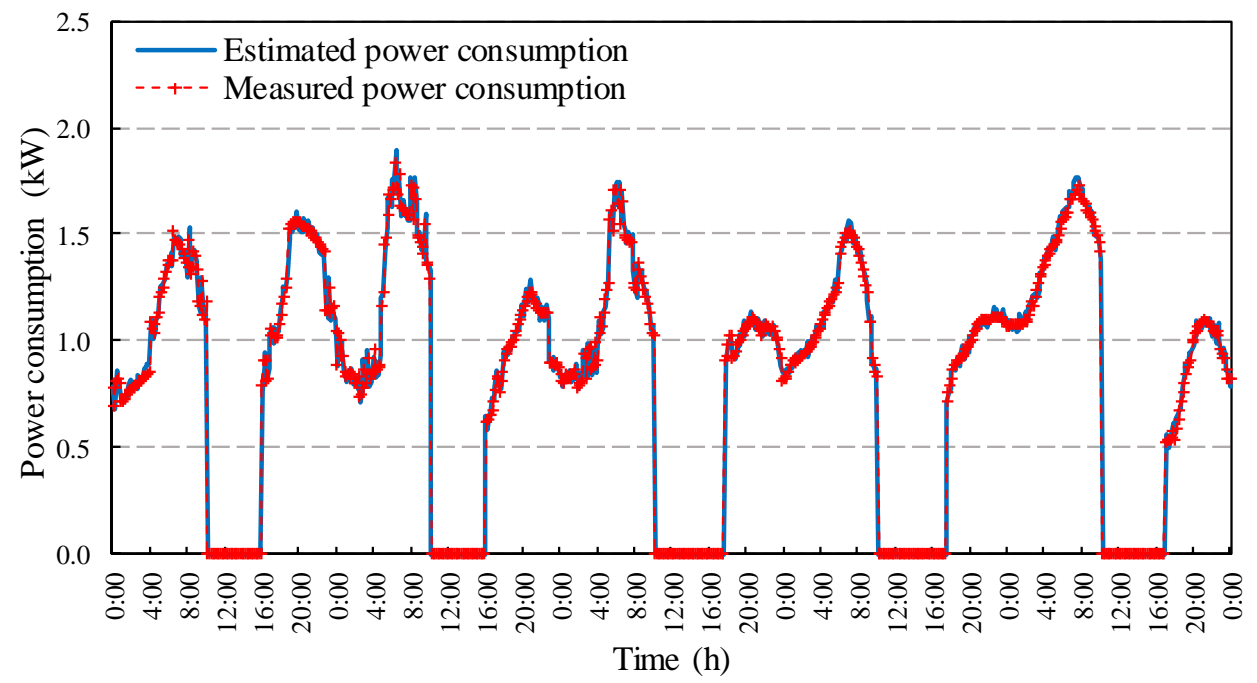

b) Heating condition

Fig. 8 Comparison between the estimated and measured power consumption of the water-to-water heat pump. 


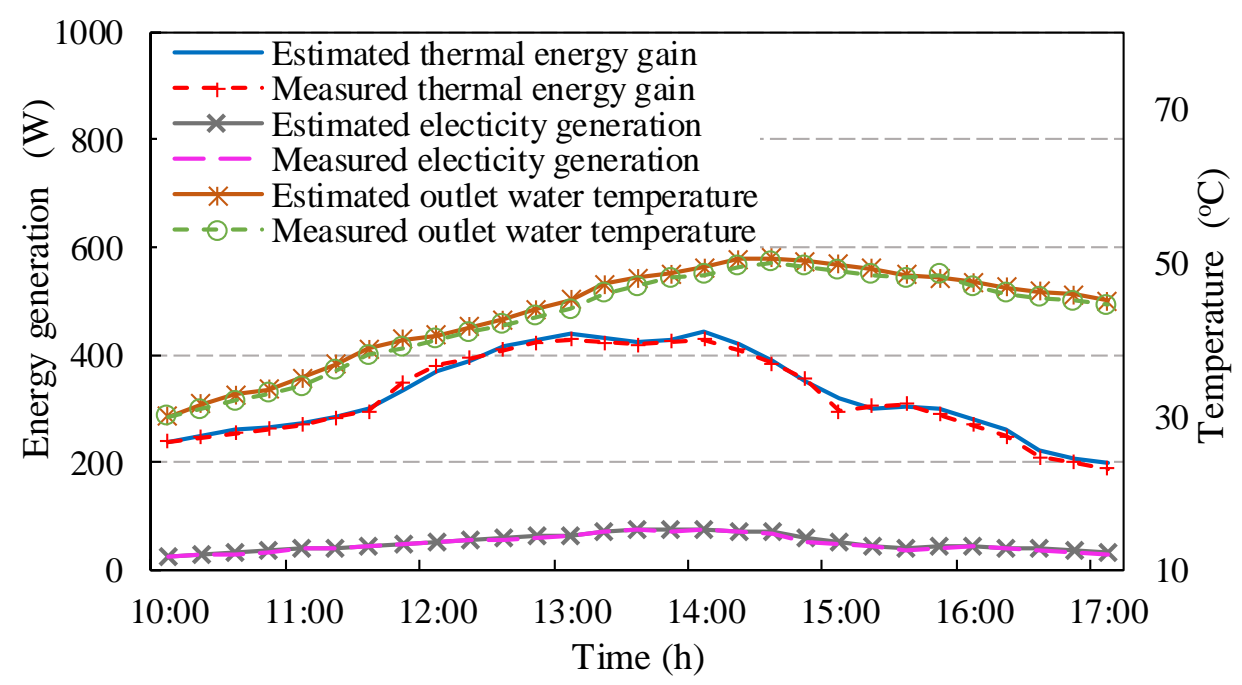

a) PVT model

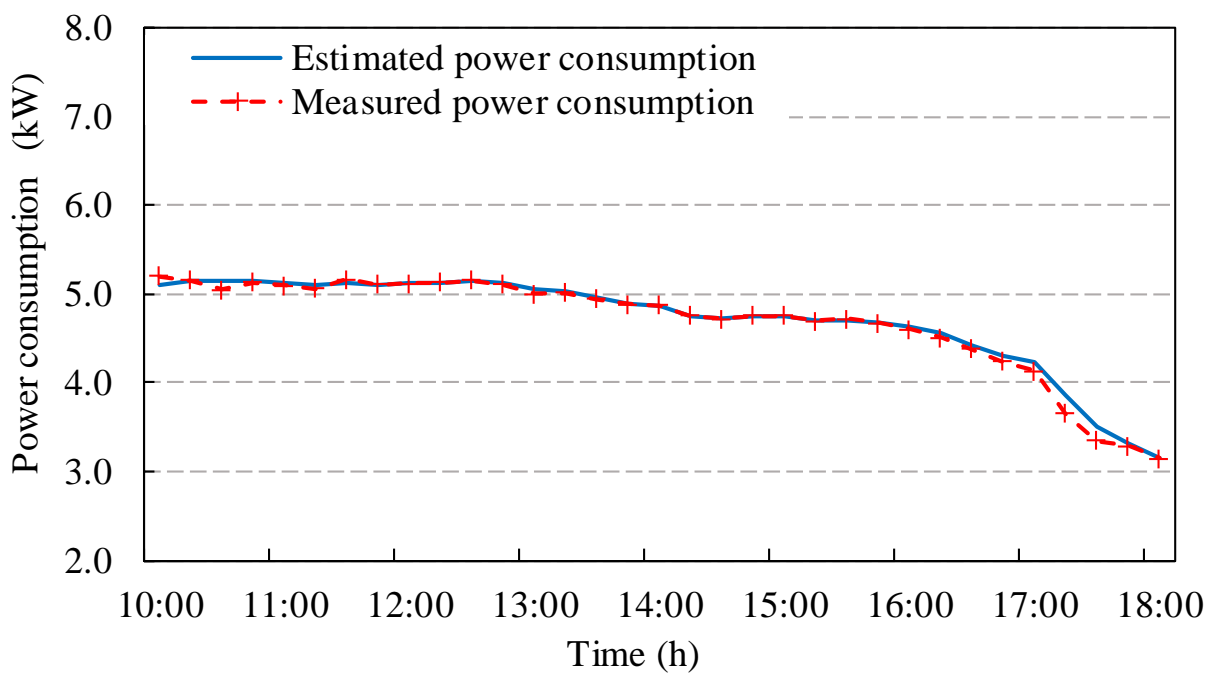

b) Water-to-water heat pump model

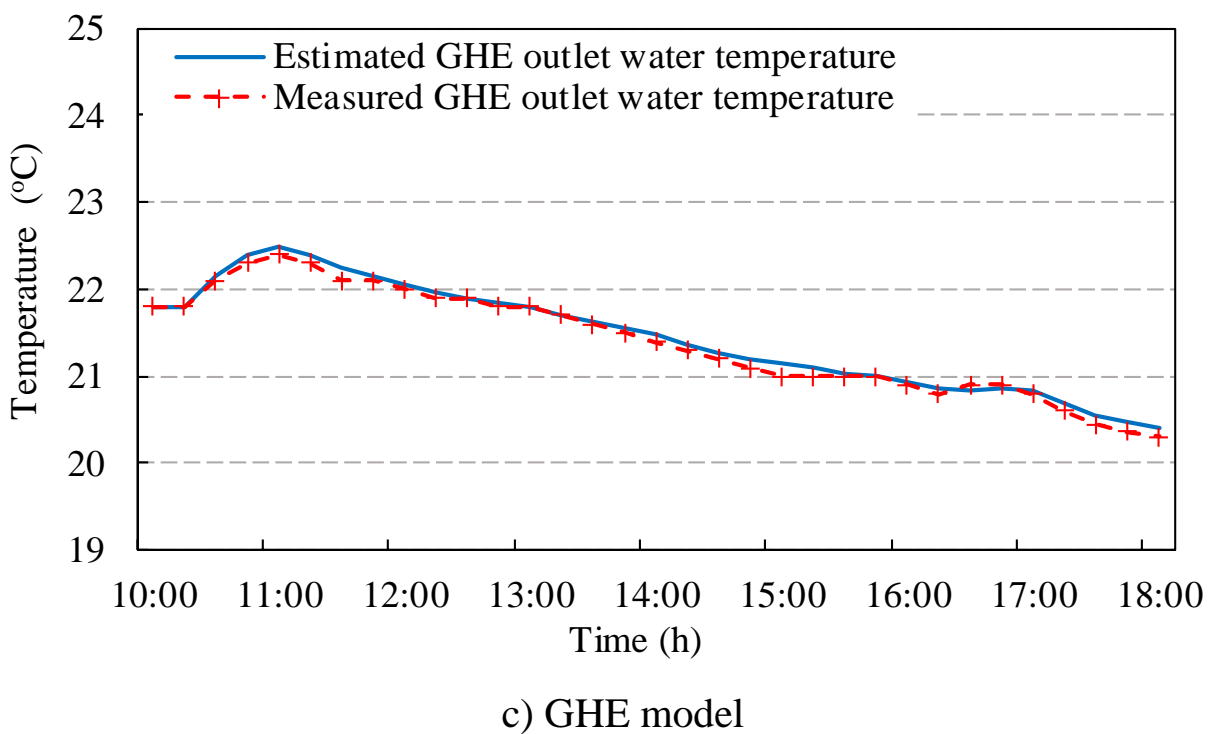

Fig. 9 Validation of the adaptive models using the performance data obtained from the 
experimental tests.

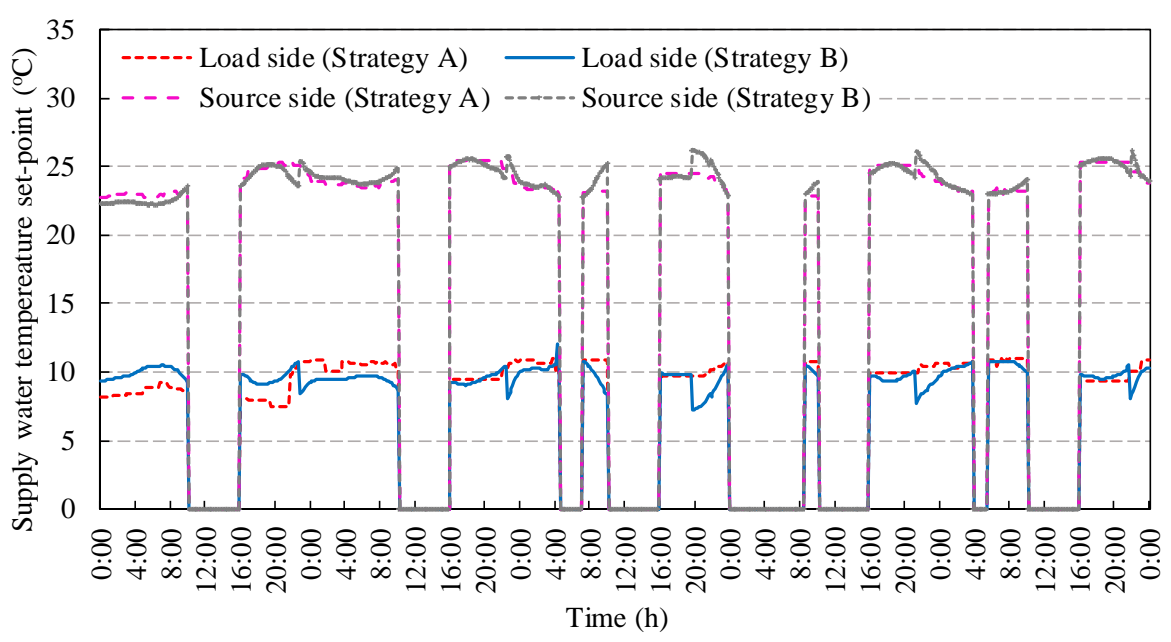

a) Temperature set-point

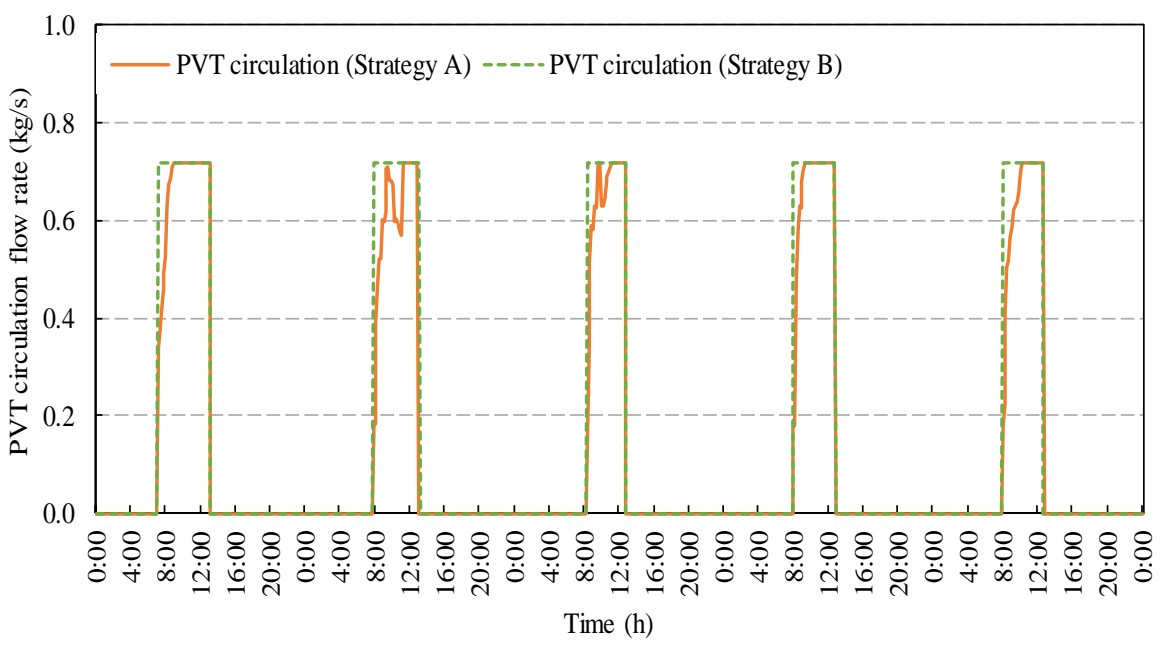

b) Water tank recharge flow rate

Fig. 10 Temperature and flow rate settings identified by using two control strategies during the cooling period. 


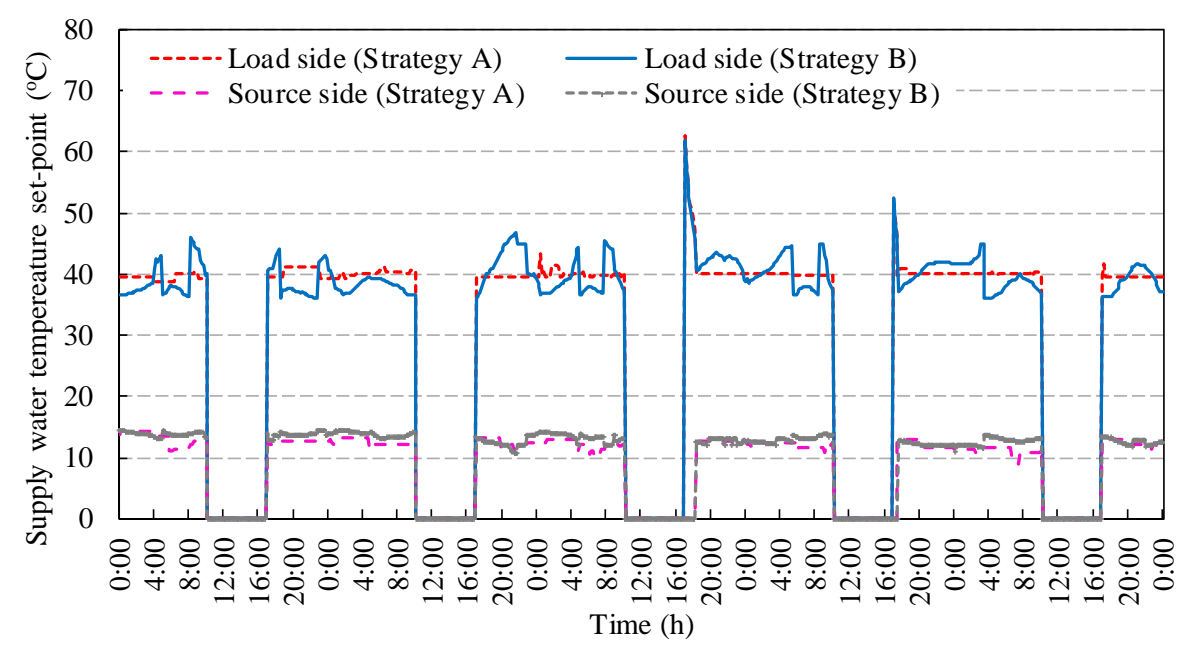

a) Temperature set-point

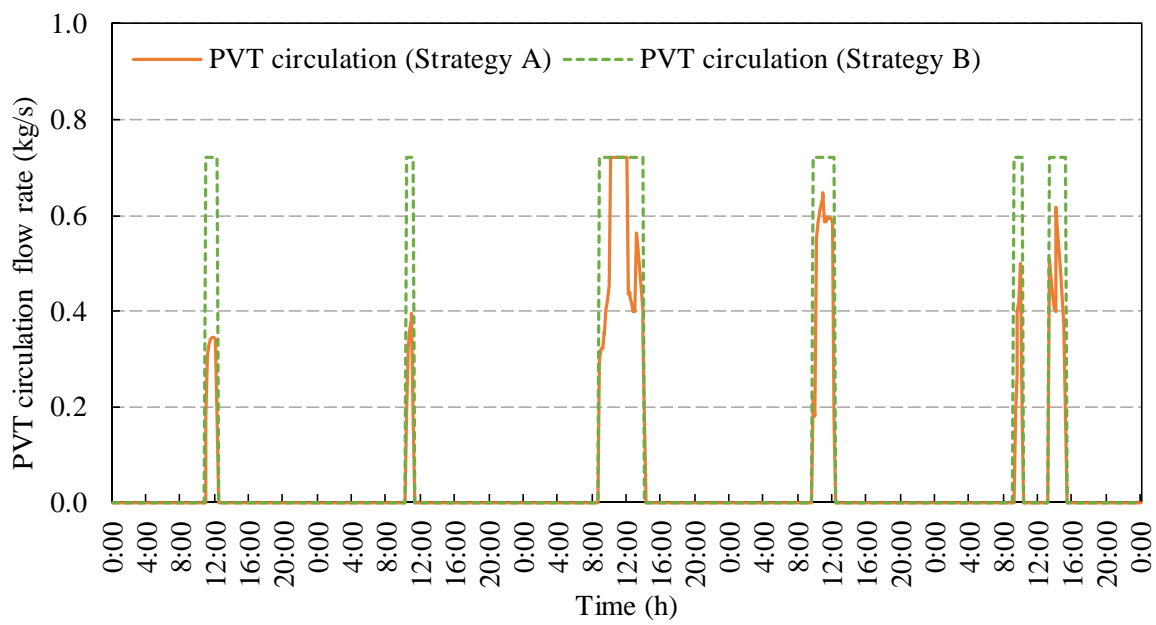

b) Water tank recharge flow rate

Fig. 11 Temperature and flow rate settings identified by using two control strategies during the heating period.

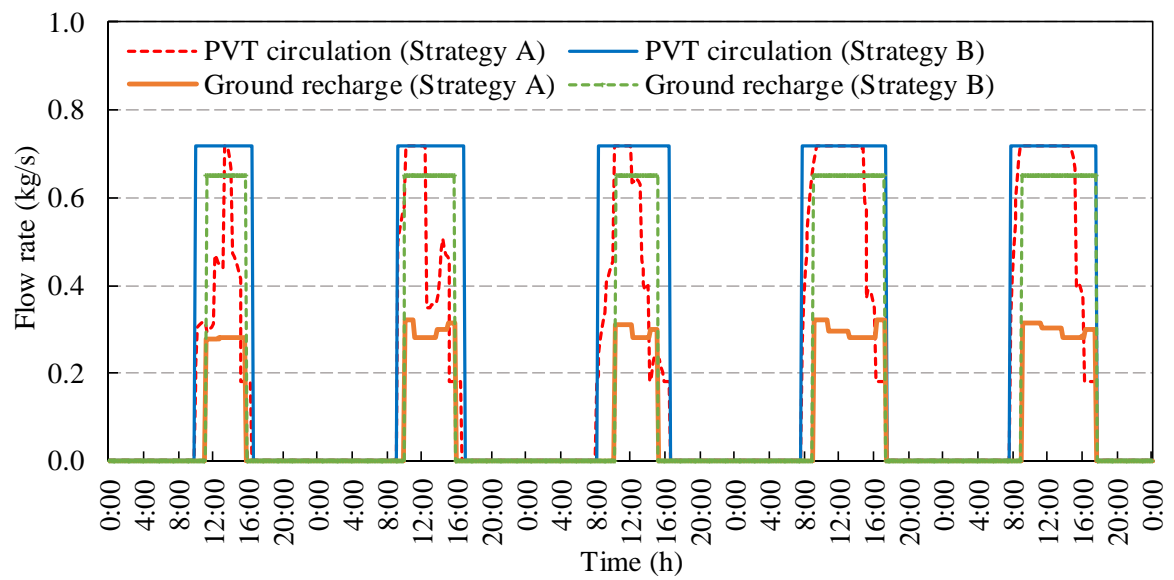

Fig. 12 Flow rate set-points identified by using the two control strategies during the transition test period. 